\title{
Bir Demir Çelik İşletmesinin Performansının Çok Kriterli Karar Verme Yöntemleri İle Değerlendirilmesi
}

\author{
Aslı Özcan 1* \\ Prof. Dr. Nuri Ömürbek²
}

Geliş tarihi: 04.04.2020

Kabul tarihi: 27.04.2020

\author{
Atıf Bilgisi \\ IBAD Sosyal Bilimler Dergisi \\ Sayı: $8 \quad$ Sayfa: $77-98$ \\ Yıl: 2020 Dönem: Güz
}

This article was checked by iThenticate. Similartiy Index $20 \%$

Bu makalede araştırma ve yayın etiğine uyulmuştur.

${ }^{1}$ Süleyman Demirel Üniversitesi, Türkiye,

aslozcn09@gmail.com.

ORCID ID: 0000-0003-2783-012X

${ }^{2}$ Süleyman Demirel Üniversitesi, Türkiye,

nuriomurbek@sdu.edu.tr

ORCID ID:0000-0002-0360-4040
ÖZ

Demir çelik ürünleri dayanıklı yatırım ve tüketim ürünleri sanayisinin temel girdisi olarak görülmektedir. Bu nedenle ülkelerin demir çelik ürünleri tüketim seviyesi o ülkedeki gelişmişliğin göstergelerinden biri olarak kabul edilebilir. Günümüzde demir çelik sektörü birçok sektöre girdi sağlayan ve ülkelerin ekonomileri için stratejik önem taşıyan bir sektör haline gelmiştir. Türkiye'de ve dünyada ekonomik açıdan önemli bir yere sahip olan demir çelik sektörü günümüzde yerini ve önemini korumakla birlikte gelecekte de bu konumunu devam ettireceği tahmin edilmektedir. Çalışmanın giriș bölümünde kısaca demir çelik sektörüne, ÇKKV (Çok Kriterli Karar Verme) yöntemlerine ve uygulamada kullanılan bu yöntemlerin adımlarına yer verilmiştir. Çalışmanın uygulama bölümünde ise Türkiye'de demir çelik üretimi yapan bir işletmenin 2000-2018 yılları arası; üretim, satış, faaliyet karı, çalışan sayısı, ihracat, ithalat, net satışlar, enerji tüketimi, kapasite kullanım oranı kriterleri esas alınarak performansı ve genel durumu hakkında değerlendirmesi yapılmaktadır. Demir çelik işletmesinin performansının değerlendirilmesinde ENTROPİ yöntemiyle kriter ağırlıkları hesaplanıp daha sonra çok kriterli karar verme yöntemlerinden oldukça yaygın kullanılan TOPSIS, MULTIMOORA ve MAUT yöntemleri ile değerlendirilmesi yapılmaktadır. Performans değerlendirilmesinde kullanılan bu 3 yöntemin sonucuna bakıldığında 2018 yılının en iyi performansa sahip yıl olduğu bulgulanmıştır.

Anahtar Kelimeler: Demir Çelik, Performans, Çok Kriterli Karar Verme, ENTROPİ, TOPSIS, MULTIMOORA, MAUT

*Sorumlu yazar 


\title{
Evaluation of Performance of an Iron-Steel Operation by Multi Criteria Decision Making
} Methods

\author{
Aslı Özcan ${ }^{1^{*}}$ \\ Prof. Dr. Nuri Ömürbek²
}

First received: 04.04.2020

Accepted: 27.04.2020

\section{Citation:}

IBAD Journal of Social

Sciences

Issue: 8

Pages: $77-98$

Year: 2020 Session: Fall

This article was checked by iThenticate. Similartiy Index $20 \%$

${ }^{1}$ Süleyman Demirel University, Turkey, aslozcn09@gmail.com,

\section{ORCID ID: 0000-0003-2783-012X}

${ }^{2}$ Süleyman Demirel University, Turkey, nuriomurbek@sdu.edu.tr ORCID ID:0000-0002-0360-4040

\section{*Corresponding Author}

\begin{abstract}
Iron and steel products are seen as the main input for the durable investment and consumer goods industry. For this reason, the consumption level of iron and steel products of the countries can be considered as an indicator of the development in that country. Today, iron and steel industry has become a sector that provides input to many sectors and has a strategic importance for the economies of countries. Which has an important place in Turkey and economically in the world today, iron and steel industries together to protect the place and importance in the future is expected to resume its position. In the introduction part of this study, briefly, the iron and steel industry, MCDM (Multiple Criteria Decision Making) methods and the steps of these methods are given. In the practical part of the study from a company engaged in the production of iron and steel in 2000-2018 years in Turkey; production, sales, operating profit, number of employees, exports, imports, net sales, energy consumption, capacity utilization rate criteria are evaluated based on its performance and general condition. In the evaluation of the performance of the iron and steel business, the criteria weights are calculated with the ENTROPY method and then evaluated using TOPSIS, MULTIMOORA and MAUT methods, which are widely used among multi criteria decision making methods. Considering the results of these 3 methods used in performance evaluation, it was found that 2018 was the year with the best performance.
\end{abstract}

Keywords: Iron Steell, Performance, Multi Criteria Decision Making, ENTROPY, TOPSIS, MULTIMOORA, MAUT 


\section{GİRİş}

Geçmişten günümüze kadar insanoğlu en uygun kararı vermek için çaba harcamıştır ve hala çaba harcamaktadır. Bu yüzden karar verme sürecini en iyi şekilde gerçekleştirebilmek için çeşitli yollar ve teknikler geliştirilmeye çalışılmaktadır. Çok kriterli karar verme yöntemleri çağdaş karar verme yollarından biridir. Bu karar verme yöntemlerinin uygulanması birç̧ok alanda olduğu gibi işletme alanında da tutarlı kararlar verilmesini sağlamaktadır (Akyüz vd., 2011, s.73). Organizasyonların ekonomik performanslarını değerlendirmek için yararlandıkları; karlılık oranları, maliyet, yatırım, satış ve tüketim gibi kriterlerin yaygın olarak kullanılma sebebi performans değerlendirme çalışmalarındaki problemleri sayısal olarak değerlendirdikleri için somut sonuçlar vermektedir. Ancak sayısal verileri kapsamayan karar verme problemlerinde bu tür ölçütlerin kullanımı mümkün olmayacaktır. Bu gibi durumlarda işletmelerin finansal performanslarının ölçülmesi ve aralarında doğru seçimin yapılabilmesi amacıyla Çok kriterli karar verme yöntemleri geliştirilmiştir (Tekeş, 2002, s.1).

Çok kriterli karar verme yöntemleri, 1960'lı yıllarda karar vericilere yardımcı olma amacıyla geliştirilmeye başlanmıştır. Bu yöntemlerin geliştirilmesindeki amaç alternatif ve kriterlerin çok fazla olduğu problemlerde verilen kararların daha hızlı ve kolay bir şekilde elde edilmesini sağlamaktır (Ball1, 2005, s. 12). Çok kriterli karar verme yöntemleri; nicel ve nitel kriterlere göre karar seçeneklerinin içinden en uygun olanının seçimiyle ilgilenmektedir (Cho, 2003, s. 1099). Çok kriterli karar verme yöntemlerinin ilgilendiği problemler genelde alternatifler, kriterler ve her bir kriter için hesaplanan ağırlıklar olmak üzere üç ana bileşeni içermektedir. Çok kriterli karar verme yöntemlerinin avantaj1 çok sayıda kriter ve alternatifi birlikte değerlendirmesidir (Chatterjee vd., 2010, s. 484). Çok kriterli karar verme yöntemleri (ELECTRE, TOPSIS, VIKOR, MAUT, COPRAS, UTA, MACBETH, PROMETHEE, MOORA vd.) günlük hayatımızda verdiğimiz kişisel kararlardan işletmelerin verdikleri stratejik ve kritik kararlara kadar farklı alanlarda uygulanmaktadır. Akademik literatürde değişik sektörlerde faaliyette bulunan firmaların performanslarının değerlendirilmesinde bu yöntemlerin sıklıkla tercih edildiği görülmektedir (Türkmen ve Çağıl, 2012, s. 63).

Bu çalışmada Türkiye'de demir çelik üretimi yapan bir işletmenin 2000-2018 yılları arasındaki performans1 ENTROPİ, TOPSIS, MULTIMOORA ve MAUT yöntemleri ile değerlendirilecektir. Bu yöntemlerin seçilmesinin sebebi her bir yöntemin uygulama sonucunun karşılaştırılması ve aynı zamanda yöntemler arası tutarlılığın irdelenecek olmasıdır. Değerlendirme sonucunda uygulamada kullanılan her üç yöntemin sonucunda 2018 yılının en iyi performansa sahip yıl olduğu görülmüştür. Bunun sebepleri incelendiğinde uygulamada kullanılan kriterlerden olan faaliyet karının 2018 yılında diğer yıllardan daha yüksek olduğu yatırımlar ve net satışların ikinci en büyük değerde olduğu bunu açıklar niteliktedir. Literatüre bakıldığında bir işletmenin yıllara göre performans değerlendirmesi yapılırken genelde bu yöntemlerin kullanıldığı görülmüştür. $\mathrm{Bu}$ çalışmanın diğer çalışmalardan farkı ise performans değerlendirmesinde tek bir yöntem değil birden fazla yöntem kullanılarak karşılaştırmalı analiz yapılacak olmasıdır.

\section{LITERATÜR İNCELEMESI}

ENTROPİ, TOPSIS, MULTIMOORA ve MAUT ile ilgili yapılmış olan çalışmalardan bazıları Tablo 1.'de görülmektedir.

Tablo 1. ENTROPI, TOPSIS, MULTIMOORA ve MAUT Yöntemleri ile Yapılan Bazı Çalışmalar

\begin{tabular}{|l|l|}
\hline \multicolumn{2}{|c|}{ ENTROPI Yöntemi İle İlgili Yapılan Bazı Çalışmalar } \\
\hline Deniz Taktik Füzelerinin Değerlendirmesi & (Cheng and Baker,1996:120-130) \\
\hline Nakliye Firması Seçimi & (Çakır, 2015: 199-216) \\
\hline Bursiyer Seçimi & (Canpolat vd, 2015: 538-547) \\
\hline Malzeme Seçim Süreci & (Arian ve Askan, 2016: 1-13) \\
\hline Turizm Performans Değerlendirmesi & (Karaatll, 2016: 1-12) \\
\hline \multicolumn{1}{|c|}{ TOPSIS Yöntemi İle İlgili Yapılan Bazı Çalışmalar } \\
\hline İşgören Seçimi & (Shih, Shyur ve Lee, 2007: 801-813) \\
\hline En Uygun Proje Seçimi & (Mahmoodzadeh vd., 2007: 135-140) \\
\hline
\end{tabular}


Bir Demir Çelik İşletmesinin Performansının Çok Kriterli Karar Verme Yöntemleri İle Değerlendirilmesi

\begin{tabular}{|c|c|}
\hline Kamu Bankalarının Performans Değerlendirmesi & (Demireli, 2010: 101-112) \\
\hline İşletmelerin Finansal Performans Değerlendirmesi & $\begin{array}{l}\text { (Özgüven, 2011:151-162), (Akyüz vd, } \\
\text { 2011: 73-92), (Saldanlı ve Sirma, } \\
\text { 2014: 185-202) }\end{array}$ \\
\hline Yeraltı Su Değerlerinin Ölçülmesi & (Bruyas vd., 2012:1-7) \\
\hline Fotoğraf Makinesi Seçimi & (Pawar ve Verma, 2013:51-53) \\
\hline Havayolu Şirketlerinin Performansı & (Ömürbek ve Kınay, 2013: 343-363) \\
\hline \multicolumn{2}{|c|}{ MULTIMOORA Yöntemi İle İlgili Yapılan Bazı Çalışmalar } \\
\hline Özelleştirme Uygulamalarının Değerlendirilmesi & (Brauers ve Zavadskas, 2006: 445-469) \\
\hline Binalarda İç İklim Değerlendirmesi & (Kalibatas ve Turskis, 2008: 79-83) \\
\hline Yol Dizaynı Optimizasyonu & $\begin{array}{l}\text { (Brauers, Zavadskas ve Peldschus, } \\
\text { 2008: } 541-548 \text { ) }\end{array}$ \\
\hline Tasarım Alternatifleri Seçimi & $\begin{array}{l}\text { (Kracka, Brausers ve Zavadskas, 2010: } \\
352-359 \text { ) }\end{array}$ \\
\hline Banka Şube Yeri Seçimi & $\begin{array}{l}\text { (Görener, Dinçer ve Hacıŏlu, 2013: } \\
\text { 41-52) }\end{array}$ \\
\hline \multicolumn{2}{|c|}{ MAUT Yöntemi İle İlgili Yapılan Bazı Çalışmalar } \\
\hline Uygun Yer Seçimi & (Wang, Wee ve Ofori, 2002: 625-645) \\
\hline Risk Faktörü Belirleme & (Gomez vd., 2003; 570-585) \\
\hline Üretim Tesisi Kurmak İçin Ülke Seçimi & $\begin{array}{l}\text { (Canbolat, Chelst ve Garg, 2007: 312- } \\
325 \text { ) }\end{array}$ \\
\hline Tahliye Kararlarının Alınması & (Kailiponi, 2010: 163-174) \\
\hline Uygun Havalimanı Yeri Seçimi & $\begin{array}{l}\text { (Türkoğlu ve Uygun, 2014: 1425- } \\
\text { 1433) }\end{array}$ \\
\hline Kurumsal Performans Değerlendirme & (Alp vd., 2015: 65-81) \\
\hline Finansal Performans Değerlendirme & (Öztel, 2012: 1-155) \\
\hline
\end{tabular}

Literatür incelemesi yapıldığında kriter ağırlıkları hesaplanırken ENTROPİ yönteminin sıklıkla kullanıldığ görülmektedir. Çalışmalarda kullanılan verilerin geniş ölçekli ve güncel olmasına dikkat edildiği gözlemlenmiş olup veri toplama aşamasında buna özen gösterilmiştir. Bu çalışmanın diğer çalışmalardan farklı1ığından kısaca bahsedecek olursak ENTROPİ yöntemi ile kriter ağırlıklarının hesaplanıp, TOPSIS, MULTIMOORA ve MAUT yöntemlerinde uygulanarak karşılaştırmalı analiz yapılması ve yöntemler arasındaki tutarlılığın gösterilmesidir.

\section{2. ÇOK KRITTERLI KARAR VERME}

Çok kriterli karar verme yöntemlerinde karar vericiler farklı özellikleri bulunan alternatifleri birçok kritere göre değerlendirerek sıralama yapmaktadır. Alternatifler değerlendirilirken karar vericiler veya uzmanlar tarafından kriterlerin önem dereceleri sübjektif bir şekilde belirlenmektedir. $\mathrm{Bu}$ değerlendirmelerin sonrasında kriter ağırlıkları tüm alternatiflerin kriterlere ilişkin performans değerleri ile çarpılarak alternatiflere ilişkin ağırlık değerleri ortaya çıkmaktadır (Türkmen ve Çağıl, 2012, s. 63).

Organizasyonlarda her seviyede bulunan karar vericiler, karmaşı problemleri analiz etmede çoklu kriterlere yönelmektedirler. Çok kriterli yöntemler çalışanların işlerinde karar verme süreçlerini kolaylaştırmaktadır. Karar verme süresince belirsizlik ve risk durumlarında seçeneklerin avantajlarını ve dezavantajlarını belirlemektedirler. Aynı zamanda bu yöntemler karar vericiler için etkin rekabet ortamlarında ihtiyaç duyulan stratejilerin şekillendirilmesi bakımından büyük önem arz etmektedir (Saaty, 1994, s. 19). Bu sebeple karar verme aşamalarına bilimsel yöntemlerin eklenmesi sonuçların öznel kararlardan uzaklaşılmasına ve daha güvenilir olmasına yardımcı olmaktadır. Zaman içerisinde farklı karar alma problemleriyle yüzleşen yöneticiler için zor olan kararlardan biri alternatifler kümesinin içerisinden en uygun alternatifin seçilmesidir. Bu seçim sürecine birbiriyle çelişen ve çok fazla sayıda kriter dahil olduğu için geleneksel seçim süreçlerinin uygulanması gerçekçi bir çözüm sunmamaktadır. $\mathrm{Bu}$ nedenle karar verme sürecince en güvenilir sonuçlara ulaşmak için ÇKKV yöntemleri günümüzde birçok çalışmada kullanılmaktadır (Soner ve Önüt, 2006, s.111). 


\section{ENTROPİ YÖNTEMI}

Entropi kavramını Shannon ve Weaver, (1948) bilginin içerisindeki belirsizliğin ölçülmesi olarak tanımlamıştır. Entropi yöntemi kriter ağırlıklarını hesaplamak için kullanılmaktadır. Entropi yönteminin temel fikri ise bu bilginin veri kümeleri arasındaki zitlıklardan geldiğidir. Buna göre, kriterlerin nesnel ağırlıkları, alternatiflerin her bir kritere göre çıktılarının ne kadar ayrı veya farklılaşmış olduğu yani "zıtlıklarının yoğunluğu" tarafından belirlenir. Bu zitlık ne kadar fazla olursa ilgili kriter tarafından kapsanan ve iletilen bilgi de o kadar fazla olmaktadır (Çınar, 2004, s. 103-104).

\subsection{Entropi Yönteminin Aşamaları}

Wang ve Lee (2009) Shannon'un (1948) ortaya atmış olduğu Entropi kavramını ağılık hesaplama yöntemi olarak geliştirilmiştir. Bu yöntemin adımları ise aşağıda gösterilmiştir; (Çakır ve Perçin, 2013, s. 83, Li vd, 201, s. 2087, Karami ve Johansson, 2014, s. 523-524)

\section{Adım 1: Karar matrisinin (A) oluşturulması:}

Karar matrisinin satır kısmında karar noktaları yani alternatifler sütunlarında ise kriterler yer almaktadır. Karar matrisi aşağıdaki gibidir:

$$
A_{i j}=\left[\begin{array}{cccc}
a_{11} & a_{12} & \ldots & a_{1 n} \\
a_{21} & a_{22} & \ldots & a_{2 n} \\
\cdot & & & \cdot \\
\cdot & & & \cdot \\
\cdot & & & \cdot \\
a_{m 1} & a_{m 2} & \ldots & a_{m n}
\end{array}\right]
$$

\section{Adım 2: Karar matrisinin normalizasyonu:}

Karar matrisinin birbirinden farklı ölçü birimlerindeki karşıtlıkları yok etmek amacıyla normalizasyon işlemi yapılarak $\mathrm{P}_{\mathrm{ij}}$ değeri hesaplanır.

$P_{i j=} \frac{a_{i j}}{\sum_{i=1}^{m} a_{i j}} ; \forall_{j}$

$a_{i j}$ : j. İndeks için i. alternatifin değeri;

$P_{i j}$ : i. alternatif için j. indeksin değer ölçeğidir.

\section{Adım 3: Entropi değerinin hesaplanması:}

Entropi değeri hesaplanırken kullanılan formülde ln doğal logaritmayı; $\mathrm{k}=1 / \ln (\mathrm{m})$ 'den hesaplanan ve $0 \leq \mathrm{E}_{\mathrm{j}} \leq 1$ olmasını garantileyen bir sabiti temsil etmektedir.

$E_{j=}\left(\frac{-1}{\ln (m)}\right) \sum_{i=1}^{m}\left[P_{i j} \ln P_{i j}\right] ; \forall_{j}$

Adım 4: $d_{j}$ değerinin hesaplanması:

$d_{j}=1-e_{j} ; \forall_{j}$

Burada dj, bir herhangi bir $\mathrm{X}_{\mathrm{j}}$ kriterinin doğasında olan zıtlık yoğunluğunu göstermektedir.

\section{Adım 5: Kriter ağırlıklarının $\left(w_{j}\right)$ hesaplanması:}

Entropi kriter ağırlıklarını hesaplamak için aşağıdaki formül kullanılmaktadır.

$\mathrm{w}_{\mathrm{j}}=\frac{d_{j}}{\sum_{j=1}^{n} d_{j}} ; \forall \mathrm{j}$

\section{TOPSIS YÖNTEMI}

TOPSIS (Technique for Order Preference by Similarity to Ideal Solution) yöntemi ' $\mathrm{m}$ ' sayıda alternatifi ve ' $\mathrm{n}$ ' sayıda kriteri olan çok amaçlı karar verme probleminin n-boyutlu uzaydaki m noktaları ile ifade edilebilir. (Yoon ve Hwang, 1995, s. 129). 1981 yılında Hwang ve Yoon tarafindan geliştirilen bu yöntemin amacı pozitif ideal çözüme olan en kısa mesafede ve negatif ideal çözüme olan en uzak mesafedeki alternatifin seçilmesidir. (Öktür, 2008, s. 55). 


\subsection{TOPSIS Yönteminin Așamaları}

Aşağıda TOPSIS yönteminin 6 adımdan oluşan uygulama aşamaları gösterilmektedir (Yoon ve Hwang, 1995, s. 40-41)

\section{Adım 1: Karar matrisinin (A) oluşturulması:}

Karar matrisinin satırlarında üstünlükleri sıralanmak istenen alternatifler, sütunlarında ise karar vermede kullanılacak olan kriterler bulunmaktadır. Aşağıda gösterilen A matrisi ise başlangıç matrisidir.

$A_{i j}=\left[\begin{array}{cccc}a_{11} & a_{12} & \ldots & a_{1 n} \\ a_{21} & a_{22} & \ldots & a_{2 n} \\ \cdot & & & \cdot \\ \cdot & & & \cdot \\ a_{m 1} & a_{m 2} & \ldots & a_{m n}\end{array}\right]$

\section{Adım 2: Normalize edilmiş(R) karar matrisi:}

$\mathrm{R}$ matrisi A matrisinin elemanlarından yararlanılarak ve aşağıdaki formül kullanılarak oluşturulmaktadır. Bu sayede karar matrisi normalize edilecektir.

$$
\begin{aligned}
& R_{i j}=\left[\begin{array}{cccc}
r_{11} & r_{12} & \ldots & r_{1 n} \\
r_{21} & r_{22} & \ldots & r_{2 n} \\
\cdot & & & \cdot \\
\cdot & & & \cdot \\
\cdot & & & \cdot \\
r_{m 1} & r_{m 2} & \ldots & r_{m n}
\end{array}\right] \\
& r_{i j}=\frac{a_{i j}}{\sqrt{\sum_{k=1}^{m} a_{k j}^{2}}} \quad \mathrm{i}=1 \ldots, \mathrm{m} ; \mathrm{j}=1, \ldots, \mathrm{n}
\end{aligned}
$$

\section{Adım 3: Ăgırlıklandırılmış karar matrisi (V):}

Kriterlere verilen önem derecesi doğrultusunda ağırlık değerleri $\left(\mathrm{w}_{\mathrm{i}}\right)$ belirlenir. Ağırlıkların belirlenmesinden sonra $\mathrm{R}$ matrisinin her bir sütunundaki elemanlar ilgili ağılık değerleri $\left(\mathrm{w}_{\mathrm{i}}\right)$ ile çarpılarak $\mathrm{V}$ matrisi oluşturulur.

$V_{i j}=\left[\begin{array}{cccc}w_{1} r_{11} & w_{2} r_{12} & \ldots & w_{n} r_{1 n} \\ w_{1} r_{21} & w_{2} r_{22} & \ldots & w_{n} r_{2 n} \\ \cdot & & & \cdot \\ \cdot & & & \cdot \\ \cdot & & \\ w_{1} r_{m 1} & w_{2} r_{m 2} & \ldots & w_{n} r_{m n}\end{array}\right]$
$\mathrm{V}_{\mathrm{ij}}=\mathrm{w}_{\mathrm{j} . \mathrm{r}_{\mathrm{ij}},}, \mathrm{i}=1, \ldots ., \mathrm{m} ; \quad \mathrm{j}=1, \ldots, \mathrm{n}$

\section{Adım 4: Pozitif ideal (A*) ve Negatif ideal (A*) çözümlerin oluşturulması:}

Pozitif İdeal çözüm, ağırlıklıklandırılmış karar matrisinin en iyi değerlerinden oluşurken; negatif ideal çözüm ise en kötü değerlerinden oluşmaktadır. İdeal çözüm setlerinin oluşturulması aşağıdaki denklemde gösterilmiştir.

Pozitif ideal çözüm setinin bulunması aşağıdaki denklemde gösterilmiştir.

$A^{*}=\left\{\left(\max _{i} v_{i j} \mid j \in J\right),\left(\min _{i} v_{i j} \mid j \in J^{\prime}\right\}\right.$ denklemden hesaplanacak set

$A^{*}=\left\{v_{1}^{*}, v_{2}^{*}, \ldots, v_{n}^{*}\right\}$ şeklinde gösterilebilir.

Negatif ideal çözüm setinin bulunması aşağıdaki denklemde gösterilmiştir.

$A^{-}=\left\{\left(\min _{i} v_{i j} \mid j \in J\right),\left(\max _{i} v_{i j} \mid j \in J^{\prime}\right\}\right.$ denklemden hesaplanacak set

$A^{-}=\left\{v_{1}^{-}, v_{2}^{-}, \ldots, v_{n}^{-}\right\}$şeklinde gösterilebilir. 
Adım 5: Ayırım kriterlerinin hesaplanması:

Her bir alternatifin pozitif ideal çözüme uzaklı̆̆1;

$S_{i}^{*}=\sqrt{\sum_{j=1}^{n}\left(v_{i j}-v_{j}^{*}\right)^{2}} \quad \mathrm{i}=1, . ., \mathrm{m}$

Her bir alternatifin negatif ideal çözüme uzaklığı;

$S_{i}^{-}=\sqrt{\sum_{j=1}^{n}\left(v_{i j}-v_{j}^{-}\right)^{2}} \quad \mathrm{i}=1, \ldots, \mathrm{m}$

\section{Adım 6: İdeal çözüme göreli yakınlığın hesaplanması:}

İdeal çözüme göreli yakınlığının $\left(\mathrm{C}_{\mathrm{i}}^{*}\right)$ hesaplanması aşă̆ıdaki formülde gösterilmiştir.

$C_{i}^{*}=\frac{S_{i}^{-}}{S_{i}^{-}+S_{i}^{*}} \quad \mathrm{i}=1, \ldots, \mathrm{m}$

$\mathrm{C}_{\mathrm{i}}^{*}$ değeri $\mathrm{O} \leq \mathrm{C}_{\mathrm{i}}^{*} \leq 1$ aralığında değer almaktadır. $\mathrm{C}_{\mathrm{i}}^{*}$ 'nin 1'e eşit olduğu durumlarda ilgili alternatif pozitif ideal çözüm noktasındadır. $\mathrm{C}_{\mathrm{i}}{ }^{*}$ nin 0 'a eşit olduğu durumlarda ise ilgili alternatifin negatif ideal çözüm noktasında bulunduğunu göstermektedir.

\section{MOORA YÖNTEMI}

MOORA (Multi-Objective Optimization By Ratio Analysis) yöntemi Willem Karel Brauers ve Edmundas Kazimieras Zavadskas tarafından 2006 yılında "Control and Cybernetics" adlı çalışmaları ile tanıtılmıştır. Bu yöntemi diğer yöntemlerden ayıran özellik bütün kriterleri göz önünde bulundurup değerlendirme çerçevesine alması, alternatifler ve kriterler arası tüm etkileşimleri aynı anda dikkate alması ve öznel ağırlıklı normalleştirme yerine nesnel ve yönsüz değerler kullanmasıdır. Bu yöntem uygulanırken dikkat edilmesi gereken en önemli koşullar verilerin güncel olması ve veriler arasındaki tüm ilişkiler dikkate alınmasıdır. Bununla birlikte farklı MOORA metotları uygulanarak elde edilen sonuçların bir arada değerlendirilebilmesi gerekmektedir. (Karaca, 2011, s. 24).

\subsection{MOORA Yöntemi Aşamaları}

Farklı MOORA yöntemleri (Oran Metodu, Referans Noktası Matrisi ve Tam Çarpım Formu) sonucu elde edilen sıralamaları baskınlıklarına göre değerlendirilmesini sağlayan MULTI-MOORA yöntemi araştırmaların tutarlılı̆̆ını arttırmaktadır. MOORA yönteminin adımları aşağıdaki gibi belirtilmiştir; (Brauers vd.,2008, s. 248; Brauers ve Ginevicius 2010, s. 15; Önay ve Çetin 2012, s. 94-95; Karaca, 2011, s. 26)

\section{Adım 1: Karar Matrisinin Hazırlanması:}

Karar matrisi oluşturulurken satırlarına alternatifler, sütunlarına ise kriterler yerleştirilmiştir.

\section{Adım 2: Normalizasyon işleminin Uygulanması:}

Her bir alternatifin karelerinin toplamının karekökü ile ilgili kriterler bölünmesiyle normalizasyon işlemi gerçekleştirilmiş olur.

$r_{i j}=\frac{w_{i j}}{\sqrt{\sum_{i=1}^{j} w_{i j}^{2}}}$

$i=1,2, \ldots, m$ alternatifin say1s1

$j=1,2, \ldots, n$ kriter sayıs 1

\section{Adım 3: Oran Metodu:}

Normalize edilmiş karar matrisindeki kriterlerin maksimum veya minimum olmasına göre belirlenip toplama işlemi yapılır. Toplanan maksimum kriter değerlerinden toplanan minimum kriter değerleri çıkartılır. 
$y_{i}^{*}=\sum_{j=1}^{g} x_{i j}^{*}-\sum_{j=g+1}^{n} x_{i j}^{*}$

$\mathrm{y}_{\mathrm{i}}{ }^{*} ; \mathrm{i}$ alternatifinin tüm amaçlara göre normalleştirilmiş değerlendirilmesidir. $\mathrm{y}_{\mathrm{i}}{ }^{*}$ lerin sıralanmasıyla işlem tamamlanış olur.

\section{Adım 4: Referans Noktası Yaklaşımı:}

Her bir kriter için; kriter maksimum ise maksimum noktalar, kriter minimum ise minimum noktalar belirlenerek maksimal kriter referans noktaları yani $r_{j}{ }^{\prime}$ ler belirlenir. Belirlenen bu noktalara her bir $\mathrm{x}_{\mathrm{ij}}{ }^{*}$ noktasına olan uzaklık değerleri bulunur ve bu değerler tekrar matris olarak hazırlanır.

$r_{j}-\mathrm{x}_{\mathrm{ij}} *$

$i=1,2, \ldots ., m$ alternatiflerin sayısın,

$j=1,2, \ldots \ldots, n$ kriterlerin sayısını,

$\mathrm{x}_{\mathrm{ij}}{ }^{*}=\mathrm{i}$. alternatifin $\mathrm{j}$. kriterdeki normalleştirilmiş değerini,

$\mathrm{r}_{\mathrm{j}}=\mathrm{j}$. kriterin referans noktasını göstermektedir.

Oluşturulmuş olan matrise Tchebycheff min - maks metrik işlemi uygulanır. Böylece alternatiflerin sıralama işlemi gerçekleştirilmiş olur.

$\left\{\operatorname{maksj}\left(\left|r_{j}-x_{i j}^{*}\right|\right)\right\}$

\section{Adım 5: Tam Çarpım Formu Yaklaşımı:}

Kriterlerin değerleri ve anlamları, çarpımlar şeklinde ifade edildiğinde; $\mathrm{x}_{\mathrm{ij}}$ değerleri aşağıdaki eşitliklerin yardımıyla normalleştirilir:

$U^{\prime} j=\frac{A_{j}}{B_{j}}, A_{j}=\prod_{g=1}^{i} X_{g i}, B_{j}=\prod_{k=i+1}^{n} X k j$

$U^{\prime} j:$ j. kriterin kullanılabilirliği

\section{MAUT YÖNTEMI}

Fisburn (1967) ve Keeney (1974) tarafından uygulanmaya başlanan ve çok kriterli karar verme yöntemlerinden biri olan MAUT daha sonra Loken tarafından 2007 yılında geliştirilmiştir. MAUT yöntemi birbiriyle çelişen alternatifler arasından en uygun seçimin yapılabilmesi olağan bir yol sağlamaktadır. Bu karar verme yöntemi alternatifler arasından en uygun olanın seçilebilmesi için sistematik şekilde çalışmaktadır (Kim ve Song, 2009, s. 145).

\subsection{MAUT Yönteminin Aşamaları}

MAUT yöntemi 5 adımdan oluşmaktadır. Yöntemin adımları aşağıdaki gibidir (Ishizaka ve Nemery 2012, s. 83).

Adım 1: İlk adımda karar matrisinin sütun ve satırlarını oluşturacak olan alternatifler $\left(a_{n}\right)$ ve bunların seçilmesinde yardımcı olacak nitelikler/kriterler $\left(\mathrm{x}_{\mathrm{m}}\right)$ belirlenmelidir.

Adım 2: Niteliklerden hangisinin daha baskın olduğunu belirlemek için ağırlık değerlerinin $\left(\mathrm{w}_{\mathrm{i}}\right)$ ataması yapılır. Tüm $w_{i}($ ağırlık) değerlerinin toplamı 1'e eşit olmalıdır.

$\sum_{j=1}^{q} w_{j}=1$

Adım 3: Kriterlerin değer ölçülerinin ataması yapılır. Bu atama nicel kriterler için nicel değerleri olurken nitel kriterler için ikili karşılaştırmalar göz önünde bulunarak yapılır. Tüm bunların 1şığında 5'lik 100'lük vb. sistemde değer atamaları yapılır. $\left(\mathrm{x}_{\mathrm{m}}\right)$

Adım 4: Atanan değerler karar matrisine yerleştirilerek normalize edilir. Normalizasyon işleminde öncelikle her nitelik için en iyi en kötü değerler belirlenerek en iyi değere 1, en kötü değere 0 değeri atanır ve diğer değerlerin hesaplanması için aşağıdaki formül kullanılır: 
$f_{i}\left(a_{i}\right)=\frac{f_{i}\left(a_{i}\right)-\min \left(f_{i}\right)}{\max \left(f_{i}\right)-\min \left(f_{i}\right)}$

Adım 5: Normalizasyon işleminden sonra fayda değerleri belirlenir. Fayda fonksiyonu formülü aşağıdaki gibidir:

$U\left(a_{i}\right)=\sum_{j=1}^{q} f_{j}\left(a_{i}\right) \cdot w_{j}$

$U\left(a_{i}\right)$ : Alternatifin fayda değeri

$f_{j}\left(a_{i}\right)$ : Kriterler ve alternatifler için normalize fayda değerleri

$w_{j}$ : Ağırlık değerleri

\section{BİR DEMIR-ÇELIK İŞLETMESININ 2000-2018 YILLARI PERFORMANSININ ÇOK KRITTERLİ KARAR VERME YÖNTEMLERIYYLE DEĞERLENDİILLMESİ}

Demir çelik sektörü, demir cevherinin yüksek fırınlarda eritilmesiyle ya da hurdaların ark ocakları içerisinde eritilmesiyle oluşan kütük ve slabın çeşitli işlem aşamalarından geçirilerek arzu edilen kimyasal ve fiziksel niteliklere sahip ürünler üretmeyi sağlayan bir sektördür. Özellikle inşaat, otomotiv, beyaz eşya ve demiryolu olmak üzere demir çelik sektörü tüm ürünlerin üretilmesine direkt olarak katkı sağlamaktadır (Sarıkaya, 2016, s. 6).

Bu çalışmada bir Demir çelik üretim işletmesinin 2000-2018 yılları arasındaki performansının değerlendirilmesinde kullanılan kriterlerin ağırlıkları ENTROPİ yöntemiyle hesaplanarak yıllar itibariyle performansı TOPSIS, MULTIMOORA ve MAUT yöntemleri yardımıyla sıralanacaktır. Ayrıca uygulamada kullanılan ÇKKV yöntemlerinin sonuçları karşılaştırılacaktır. Demir çelik üretim işletmesinin 2000-2018 yılları arasındaki performans değerlendirilmesinde kullanılan kriterler uzman kişiler tarafından belirlenen; üretim (ton), satış (ton), yatırım (TL), faaliyet karı (TL), çalışan sayısı, ihracat (USD), ithalat (USD), ihracat (ton), ithalat (ton), net satışlar (TL), enerji tüketimi ( $\mathrm{m}_{\text {cal }} /$ ton) ve kapasite kullanım oranı (\%)'dır. Değerlendirmede kullanılacak olan 12 kriter üretim yapan işletmeler için performans değerlendirmesini büyük ölçüde etkilediği düşünülmektedir. İhracat ve ithalat kriterleri arasındaki korelasyon katsayısına bakıldığında güçlü bir ilişki tespit edildiği için dolar ve ton bazında ayrı ayrı ele alınmıştır. Değerlendirmede kullanılacak kriterler, kriterlerin kodları ve kriterlerin birimleri Tablo 2.' de görülmektedir. Bir sonraki aşamada bu kriterlerin verileri, Demir çelik üretim işletmesinin web sayfasındaki faaliyet raporlarından ve eksik olan verileri ise işletme bünyesindeki yetkili kişilerden elde edilerek karar matrisi oluşturulmuştur. Oluşturulan bu matriste nesnel ağırlık hesaplama yöntemi olan ENTROPİ yöntemi ile ağırlıkları belirlenmiştir. ENTROPI yöntemiyle belirlenen kriter ağıllıkları sırasıyla TOPSIS, MULTIMOORA ve MAUT yöntemlerinde kullanılarak işletmenin yıllara göre performans değerlendirilmesi yapılacaktır.

Tablo 2. Kodlar, Kriterler ve Birimleri

\begin{tabular}{lll}
\hline Kod & Kriterler & Birimi \\
\hline K1 & Üretim & Ton \\
K2 & Satış & Ton \\
K3 & Yatırım & Türk Lirası \\
K4 & Faaliyet Karı & Türk Lirası \\
K5 & Çalışan Sayısı & Kişi \\
K6 & İhracat & Amerikan Doları (USD) \\
K7 & İthalat & Amerikan Doları (USD) \\
K8 & İhracat & Ton \\
K9 & İthalat & Ton \\
K10 & Net Satışlar & Türk Lirası \\
K11 & Enerji Tüketimi & Mcal/ton \\
K12 & Kapasite Kullanım Oranı & \% \\
\hline
\end{tabular}

\subsection{Entropi Yöntemi İle Kriter Ağırlıklarının Hesaplanması}

Kriter ağırlıklarının hesaplanmasında kullanılan ENTROPİ yönteminin adımları aşağıda açıklanmıştır. 


\section{Adım 1: Karar Matrisi Oluşturulması:}

Demir çelik üretim işletmesinin 2000-2018 yılları arasındaki faaliyet raporları ve yetkililerden alınan verilere göre düzenlenen karar matrisi Tablo 3.' teki gibidir.

Tablo 3. Karar Matrisi

\begin{tabular}{|c|c|c|c|c|c|c|c|c|c|c|c|c|}
\hline & $\max$ & $\max$ & $\max$ & $\max$ & $\min$ & $\max$ & $\min$ & $\max$ & $\min$ & $\max$ & $\min$ & $\max$ \\
\hline YILLAR & K1 & K2 & K3 & K4 & K5 & K6 & K7 & K8 & K9 & K10 & K11 & K12 \\
\hline 2000 & 614309 & 894860 & 16941362 & 6016828 & 4834 & 1559 & 1932 & 6975 & 6223 & 113658328 & 7141 & 74,87 \\
\hline 2001 & 445894 & 752241 & 14333359 & 7508130 & 4344 & 2029 & 1203 & 9676 & 4227 & 161466920 & 6632 & 58,44 \\
\hline 2002 & 201995 & 549449 & 17192793 & 18242974 & 3919 & 2219 & 1693 & 10105 & 5494 & 169189513 & 7185 & 41,2 \\
\hline 2003 & 374464 & 804846 & 21544571 & 15666586 & 4098 & 2899 & 2660 & 10450 & 6820 & 317586275 & 6654 & 63,41 \\
\hline 2004 & 797261 & 834369 & 61472451 & 104737475 & 3997 & \begin{tabular}{|l|}
5209 \\
\end{tabular} & 4579 & 12130 & 7994 & 494726176 & 7347 & 62,85 \\
\hline 2005 & 966471 & 932948 & 37622908 & 7012398 & 3502 & 7600 & 7039 & 13331 & 10098 & 491014440 & 6709 & 75,88 \\
\hline 2006 & 1029486 & 1076246 & 132320672 & 108486490 & 3408 & 9406 & 8616 & 15353 & 12313 & 701795904 & 6857 & 83,86 \\
\hline 2007 & 1025675 & 969616 & 114946362 & 146639794 & 3299 & 12239 & 11481 & 16696 & 13946 & 743040715 & 7014 & 68,4 \\
\hline 2008 & 1058507 & 1016254 & 165030103 & 346531894 & 3190 & 20456 & 15013 & 19956 & 13587 & 1081439583 & 6855 & 43,13 \\
\hline 2009 & 1087893 & 1043150 & 49346211 & 71990373 & 3319 & 12007 & 7952 & 18736 & 10460 & 793562999 & 6360 & 81,67 \\
\hline 2010 & 1140614 & 1138473 & 128936931 & 30601713 & 4188 & 13321 & 9969 & 17638 & 11043 & 1008861255 & 6502 & 87,6 \\
\hline 2011 & 1417202 & 1363682 & 140496294 & 232120669 & 4002 & 16610 & 11821 & 18513 & 10684 & 1590849528 & 6342 & 107,43 \\
\hline 2012 & 1478184 & 1424886 & 334957800 & 220741196 & 3877 & 17152 & 11232 & 20294 & 11842 & 1686666273 & 6248 & 115,26 \\
\hline 2013 & 1622578 & 1554738 & 418478836 & 198125460 & 3741 & 15788 & 12818 & 18967 & 14858 & 1812224881 & 6073 & 66,42 \\
\hline 2014 & 1740055 & 1732970 & 607685115 & 443991991 & 3528 & 15183 & 12006 & 17969 & 13808 & 2188972410 & 5722 & 73,58 \\
\hline 2015 & 2080767 & 1934969 & 665788944 & 82619865 & 3608 & 11752 & 12320 & 16758 & 19063 & 2230892163 & 5940 & 71,75 \\
\hline 2016 & 2076736 & 2063827 & 345715634 & 136487839 & 3906 & 10876 & 10900 & 16900 & 17500 & 2336737097 & 5452 & 93,4 \\
\hline 2017 & 2295200 & 2326421 & 252570316 & 499049133 & 4176 & 13440 & 12440 & 18300 & 16300 & 3972625977 & 5670 & 95,3 \\
\hline 2018 & 2314794 & 2198974 & 413550136 & 1632956078 & 4027 & 17755 & 12855 & 22100 & 14500 & 5582800586 & 5546 & 97,09 \\
\hline
\end{tabular}

\section{Adım 2: Normalize Edilmiş Karar Matrisi}

Karar matrisinin normalleştirilmesi için Tablo 3.'te gösterilen değerler eşitlik (1) yardımıyla ilgili kriterlerin toplamına ilgili yılın kriter değerleri bölünerek normalizasyon işlemi gerçekleştirilmiştir. Normalize edilmiş karar matrisi Tablo 4.’te gösterildiği gibidir.

Tablo 4. Normalize Edilmiş Karar Matrisi

\begin{tabular}{|c|c|c|c|c|c|c|c|c|c|c|c|c|}
\hline YILLAR & K1 & K2 & K3 & K4 & K5 & K6 & K7 & K8 & K9 & K10 & K11 & K12 \\
\hline 2000 & 0,02585 & 0,03636 & 0,00430 & 0,00140 & 0,06625 & 0,00751 & 0,01146 & 0,02318 & 0,02819 & 0,00414 & 0,05841 & 0,05123 \\
\hline 2001 & 0,01876 & 0,03056 & 0,00364 & 0,00174 & 0,05954 & 0,00978 & 0,00714 & 0,03216 & 0,01915 & 0,00588 & 0,05425 & 0,03999 \\
\hline 2002 & 0,00850 & 0,02232 & 0,00436 & 0,00423 & 0,05371 & 0,01069 & 0,01005 & 0,03359 & 0,02489 & 0,00616 & 0,05877 & 0,02819 \\
\hline 2003 & 0,01575 & 0,03270 & 0,00547 & 0,00364 & 0,05617 & 0,01397 & 0,01578 & 0,03474 & \begin{tabular}{|l|}
0,03089 \\
\end{tabular} & 0,01156 & 0,05443 & 0,04339 \\
\hline 2004 & 0,03354 & 0,03390 & 0,01561 & 0,02430 & 0,05478 & 0,02510 & 0,02717 & 0,04032 & 0,03621 & 0,01800 & 0,06010 & 0,04300 \\
\hline 2005 & 0,04066 & 0,03790 & 0,00955 & 0,00163 & 0,04800 & 0,03663 & 0,04177 & 0,04431 & 0,04574 & 0,01787 & 0,05488 & 0,05192 \\
\hline 2006 & 0,04331 & 0,04373 & \begin{tabular}{|l|}
0,03359 \\
\end{tabular} & 0,02517 & 0,04671 & 0,04533 & 0,05112 & 0,05103 & 0,05578 & 0,02554 & 0,05609 & 0,05738 \\
\hline 2007 & 0,04315 & 0,03939 & 0,02918 & 0,03403 & 0,04521 & 0,05898 & 0,06812 & 0,05550 & 0,06317 & 0,02704 & 0,05737 & 0,04680 \\
\hline 2008 & 0,04453 & 0,04129 & 0,04190 & 0,08041 & 0,04372 & 0,09858 & 0,08908 & 0,06633 & 0,06155 & 0,03936 & 0,05607 & 0,02951 \\
\hline 2009 & 0,04577 & 0,04238 & 0,01253 & 0,01670 & 0,04549 & 0,05787 & 0,04718 & 0,06228 & 0,04738 & 0,02888 & 0,05203 & 0,05588 \\
\hline 2010 & 0,04799 & 0,04626 & 0,03273 & 0,00710 & 0,05740 & 0,06420 & 0,05915 & 0,05863 & \begin{tabular}{|l|}
0,05002 \\
\end{tabular} & 0,03672 & 0,05319 & 0,05994 \\
\hline 2011 & 0,05963 & 0,05541 & 0,03567 & 0,05386 & 0,05485 & 0,08005 & 0,07014 & 0,06154 & 0,04840 & 0,05790 & 0,05188 & 0,07350 \\
\hline 2012 & 0,06219 & 0,05789 & 0,08504 & 0,05122 & 0,05314 & 0,08266 & 0,06665 & 0,06746 & 0,05364 & 0,06138 & 0,05111 & 0,07886 \\
\hline 2013 & 0,06827 & 0,06317 & 0,10624 & 0,04597 & 0,05127 & 0,07609 & 0,07606 & 0,06305 & 0,06730 & 0,06595 & 0,04968 & 0,04545 \\
\hline 2014 & 0,07321 & 0,07041 & \begin{tabular}{|l|}
0,15428 \\
\end{tabular} & 0,10303 & 0,04835 & 0,07317 & 0,07124 & 0,05973 & 0,06255 & 0,07966 & 0,04681 & 0,05034 \\
\hline 2015 & 0,08754 & 0,07862 & 0,16903 & 0,01917 & 0,04945 & 0,05664 & 0,07310 & 0,05570 & 0,08635 & 0,08119 & 0,04859 & 0,04909 \\
\hline 2016 & 0,08738 & 0,08385 & 0,08777 & 0,03167 & 0,05353 & 0,05241 & 0,06468 & 0,05617 & 0,07927 & 0,08504 & 0,04460 & 0,06391 \\
\hline 2017 & 0,09657 & 0,09452 & 0,06412 & 0,11580 & 0,05723 & 0,06477 & 0,07382 & 0,06083 & 0,07384 & 0,14457 & 0,04638 & 0,06521 \\
\hline 2018 & 0,09739 & 0,08934 & 0,10499 & 0,37892 & 0,05519 & 0,08557 & 0,07628 & 0,07346 & 0,06568 & 0,20317 & 0,04537 & 0,06643 \\
\hline
\end{tabular}

\section{Adım 3: $E_{j}$ ve K Değerinin Hesaplanması:}

Her bir kriterin kendi değerinin $\left(\mathrm{R}_{\mathrm{ij}}\right)$ doğal logaritması hesaplanarak $\left(\ln _{\mathrm{ij}}\right)$ bu değerler birbirleriyle çarpılmıştır $\left(\mathrm{R}_{\mathrm{ij}} \mathrm{XLn} \mathrm{ij}_{\mathrm{j}}\right)$. $\mathrm{E}_{\mathrm{j}}$ değeri eşitlik (2) yardımıyla hesaplanarak Tablo 5.'te gösterilmiştir. $\mathrm{K}=1 / \mathrm{ln} . n$ - $1 / \ln 19=0,33962 \mathrm{k}$ burada bir sabit sayı olmak üzere $\mathrm{e}_{\mathrm{ij}}$ değerinin 0 ile 1 arasında olmasını sağlamaktadır $(0 \leq$ eij $\leq 1)$. Logaritmik değerler normalize değerler ile çarpılarak toplanır. Toplanan değerler son aşamada ' $k$ ' yani entropi katsayısı ile çarpılarak tablo düzenlenir. Ele alınan alternatif sayısının logaritmik hali " $k$ " yani entropi katsayısıdır.

Tablo 5. $E_{i j}$ Değerleri

\begin{tabular}{|l|l|l|l|l|l|l|l|l|l|l|l|l|}
\hline $\mathbf{e}_{\mathbf{i j}}$ & 0,95448 & 0,97392 & 0,85045 & 0,73572 & 0,99814 & 0,94446 & 0,95048 & 0,98770 & 0,978287 & 0,86817 & 0,99868 & 0,98922 \\
\hline
\end{tabular} 


\section{Adım 4: $D_{\mathrm{ij}}$ Değerinin Hesaplanması:}

Eşitlik (3) yardımıyla yukarıda hesaplanmış olan $\mathrm{e}_{\mathrm{ij}}$ değerleri 1'den çıkarılarak $\mathrm{d}_{\mathrm{ij}}$ değerleri hesaplanır. Hesaplanan değerler Tablo 6.'da gösterilmiştir.

Tablo 6. $D_{i j}$ Değerleri

\begin{tabular}{|l|l|l|l|l|l|l|l|l|l|l|l|l|l|}
\hline $\mathbf{d}_{\mathbf{i j}}$ & 0,04551 & 0,02607 & 0,14954 & 0,26427 & 0,00186 & 0,05554 & 0,04952 & 0,01229 & 0,02171 & 0,13182 & 0,00131 & 0,01077 & 0,77023 \\
\hline
\end{tabular}

\section{Adım 5: Kriter: Ă̆ırlıklarının Hesaplanması:}

Kriter ağılıkları eşitlik (4) yardımıyla hesaplanmıştır. Entropi Kriter ağırlık değerleri Tablo 7.' de gösterildiği gibidir.

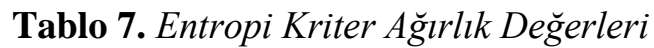

\begin{tabular}{|c|c|c|c|c|c|c|c|c|c|c|c|c|}
\cline { 2 - 12 } \multicolumn{1}{c|}{} & K1 & K2 & K3 & K4 & K5 & K6 & K7 & K8 & K9 & K10 & K11 & K12 \\
\hline Wj & 0,05909 & 0,03385 & 0,19416 & 0,34311 & 0,00241 & 0,07211 & 0,06429 & 0,01596 & 0,02819 & 0,17115 & 0,00170 & 0,01399 \\
\hline
\end{tabular}

Tablo 7.' ye bakıldığında en yüksek ağırlığa (0,34311) sahip olan kriter Faaliyet Karı (K4) en önemli performans kriteri olarak değerlendirilebilir. Bu kriteri takiben Yatırım (K3) ikinci en önemli kriterdir. Faaliyet karı ve yatırım kriterlerinin Demir çelik üretim işletmesi performansının belirlemesi bakımından ön planda olan ilk iki kriterlerdir. En düşük ağırlığa sahip olan Enerji Tüketimi (K11) performans değerlendirmesi yapılırken etkisi en düşük kriter olarak değerlendirilebilir.

\subsection{Entropi Ă̆ırlıklarıyla TOPSIS Yönteminin Uygulanması}

TOPSIS yönteminin adımları aşağıda verilmiştir.

\section{Adım 1: Karar Matrisinin Oluşturulması:}

Demir çelik üretim işletmesinin 2000-2018 yılları arasındaki faaliyet raporları ve yetkililerden alınan verilere göre düzenlenen karar matrisi Tablo 3.' teki gibidir.

\section{Adım 2: Karar Matrisinin Normalizasyonu:}

Eşitlik (5) yardımıyla karar matrisinin sütunlarındaki her bir değerin ilgili sütundaki bütün değerlerin karelerinin toplamının kareköküne bölünüp tek bir paydaya indirgenmesiyle hesaplanmıştır. Normalize edilmiş karar matrisi Tablo 8.'de gösterilmiştir.

Tablo 8. Normalize Edilmiş Karar Matrisi

\begin{tabular}{|c|c|c|c|c|c|c|c|c|c|c|c|c|}
\hline YILLAR & K1 & K2 & K3 & K4 & K5 & K6 & K7 & K8 & K9 & K10 & K11 & K12 \\
\hline 2000 & 0,10077 & 0,14719 & 0,01358 & 0,00324 & 0,28721 & 0,02902 & 0,04498 & 0,09786 & 0,11611 & 0,01309 & 0,25365 & 0,21668 \\
\hline 2001 & 0,07314 & 0,12373 & 0,01149 & 0,00404 & 0,25810 & 0,03777 & 0,02801 & 0,13575 & 0,07887 & 0,01860 & 0,23557 & 0,16913 \\
\hline 2002 & 0,03313 & 0,09038 & 0,01378 & 0,00982 & 0,23285 & 0,04131 & 0,03942 & 0,14177 & 0,10251 & 0,01949 & 0,25521 & 0,11924 \\
\hline 2003 & 0,06142 & 0,13239 & 0,01726 & 0,00843 & 0,24348 & 0,05397 & 0,06193 & 0,14661 & 0,12725 & 0,03659 & 0,23635 & 0,18351 \\
\hline 2004 & 0,13078 & 0,13724 & 0,04926 & 0,05638 & 0,23748 & 0,09698 & 0,10661 & 0,17018 & 0,14915 & 0,05699 & 0,26097 & 0,18189 \\
\hline 2005 & 0,15853 & 0,15346 & 0,03015 & 0,00377 & 0,20807 & 0,14149 & 0,16389 & 0,18703 & 0,18841 & 0,05656 & 0,23830 & 0,21960 \\
\hline 2006 & 0,16887 & 0,17703 & 0,10603 & 0,05840 & 0,20249 & 0,17511 & 0,20061 & 0,21540 & 0,22973 & 0,08085 & 0,24356 & 0,24270 \\
\hline 2007 & 0,16824 & 0,15949 & 0,09211 & 0,07893 & 0,19601 & 0,22785 & 0,26732 & 0,23424 & 0,26020 & 0,08560 & 0,24914 & 0,19795 \\
\hline 2008 & 0,17363 & 0,16716 & 0,13224 & 0,18653 & 0,18953 & 0,38083 & 0,34955 & 0,27998 & 0,25350 & 0,12458 & 0,24349 & 0,12482 \\
\hline 2009 & 0,17845 & 0,17159 & 0,03954 & 0,03875 & 0,19720 & 0,22353 & 0,18515 & 0,26287 & 0,19516 & 0,09142 & 0,22591 & 0,23636 \\
\hline 2010 & 0,18710 & 0,18727 & 0,10332 & 0,01647 & 0,24883 & 0,24800 & 0,23211 & 0,24746 & 0,20604 & 0,11622 & 0,23095 & 0,25352 \\
\hline 2011 & 0,23246 & 0,22431 & 0,11258 & 0,12495 & 0,23778 & 0,30923 & 0,27523 & 0,25974 & 0,19934 & 0,18326 & 0,22527 & 0,31091 \\
\hline 2012 & 0,24247 & 0,23438 & 0,26840 & 0,11882 & 0,23035 & 0,31932 & 0,26152 & 0,28472 & 0,22095 & 0,19430 & 0,22193 & 0,33357 \\
\hline 2013 & 0,26615 & 0,25574 & 0,33533 & 0,10665 & 0,22227 & 0,29392 & 0,29845 & 0,26611 & 0,27722 & 0,20877 & 0,21571 & 0,19222 \\
\hline 2014 & 0,28542 & 0,28505 & 0,48694 & 0,23900 & 0,20961 & 0,28266 & 0,27954 & 0,25211 & 0,25763 & 0,25217 & 0,20325 & 0,21295 \\
\hline 2015 & 0,34131 & 0,31828 & 0,53350 & 0,04447 & 0,21437 & 0,21879 & 0,28685 & 0,23511 & 0,35567 & 0,25700 & 0,21099 & 0,20765 \\
\hline 2016 & 0,34065 & 0,33947 & 0,27702 & 0,07347 & 0,23207 & 0,20248 & 0,25379 & 0,23711 & 0,32651 & 0,26919 & 0,19366 & 0,27031 \\
\hline 2017 & 0,37648 & 0,38267 & 0,20239 & 0,26863 & 0,24812 & 0,25021 & 0,28965 & 0,25675 & 0,30412 & 0,45764 & 0,20140 & 0,27580 \\
\hline 2018 & 0,37970 & 0,36171 & 0,33138 & 0,87900 & 0,23926 & 0,33054 & 0,29931 & 0,31006 & 0,27054 & 0,64313 & 0,19699 & 0,28099 \\
\hline
\end{tabular}

\section{Adım 3: Ağırlıklandırılmış Karar Matrisi:}

Eşitlik (6) yardımıyla karar matrisinde bulunan değerlerin ilgili ağırlık katsayıları (w) ile çarpılmasıyla ağırlıklandırılmış karar matrisi elde edilir. Ağılıklandırılmış Karar Matrisi, Kriter Ağıllıkları, pozitif ve negatif ideal çözüm setleri $\left(\mathrm{S}^{*}, \mathrm{~S}^{-}\right)$Tablo 9.' da gösterilmektedir. 


\section{Adım 4: Pozitif ve Negatif İdeal Çözümler:}

Ağırlıklandırılmış matriste her bir kriterin ilgili olduğu sütundan pozitif ideal çözüm için pozitif ideal ve negatif ideal çözüm için de negatif ideal değerler tespit edilerek pozitif ve negatif ideal çözüm setleri belirlenir. Her bir kriter için pozitif ve negatif ideal çözüm setleri Tablo. 9' da gösterilmektedir.

Tablo 9. Ă̆ırlıklandırılmış Karar Matrisi

\begin{tabular}{|c|c|c|c|c|c|c|c|c|c|c|c|c|}
\hline $\mathbf{W}_{\mathbf{j}}$ & 0,05909 & 0,03385 & 0,19416 & 0,34311 & 0,00241 & 0,07211 & 06429 & 0,01596 & 0,02819 & 0,17115 & 0,00170 & 0,01399 \\
\hline YILLAR & K1 & K2 & K3 & K4 & K5 & K6 & K7 & K8 & K9 & K10 & K11 & K12 \\
\hline 2000 & 0,00595 & 0,00498 & 0,00264 & 0,00111 & 0,00069 & 0,00209 & 0,00289 & 0,00156 & 0,00327 & 0,00224 & 0,00043 & 0,00303 \\
\hline 2001 & 0,00 & 0,00419 & 0,00223 & 139 & 0,00062 & 272 & & 0,00217 & 0,00222 & 0,00318 & 0,00040 & 0,00237 \\
\hline 2002 & 0,00196 & 0,00306 & 0,00267 & 0,00337 & 0,00056 & 0,00298 & 0,00253 & 0,00226 & 0,00289 & 0,00334 & 0,00043 & 0,00167 \\
\hline 2003 & 0,00363 & 0,00448 & 0,00335 & 0,00289 & 0,00059 & 0,00389 & 0,00398 & 0,00234 & 0,00359 & 0,00626 & 0,00040 & 0,00257 \\
\hline 2004 & 0,00773 & 0,00465 & 0,00956 & 0,01934 & 0,00057 & 0,00699 & 0,00685 & 0,00272 & 0,00420 & 0,00975 & 0,00044 & 0,00254 \\
\hline 2005 & 0,00937 & 0,00519 & 0,00585 & 0,00130 & 0,00050 & 0,01020 & 0,01054 & 0,00298 & 0,00531 & 0,00968 & 0,00041 & 0,00307 \\
\hline 2006 & 0,00998 & 0,00599 & 0,02059 & 0,02004 & 0,00 & 0,0 & 90 & 0,0 & 0,0 & 0,01384 & 941 & 0,00339 \\
\hline 2007 & 0,0 & 0,00540 & 0,0 & 0,02708 & 0,00047 & 43 & 18 & 374 & 0,0 & 465 & 042 & 0,00277 \\
\hline 2008 & 0,01026 & 0,00566 & 0,02568 & 0,06400 & 0,00046 & 0,02746 & 0,02247 & 0,00447 & 0,00715 & 0,02132 & 0,00041 & 0,00175 \\
\hline 2009 & 0,01054 & 0,00581 & 0,00768 & 0,01330 & 0,00048 & 0,01612 & 0,01190 & 0,00420 & 0,00550 & 0,01565 & 038 & 0,00331 \\
\hline 2010 & 0,01106 & 0,00634 & 0,02006 & 0,00565 & 0,00060 & 0,01788 & 0,01492 & 0,00395 & 0,00581 & 0,01989 & 0,00039 & 0,00355 \\
\hline 2011 & 0,01374 & 0,00759 & 0,02186 & 0,04287 & 0,00057 & 0,02230 & 0,01769 & 0,00415 & 0,00562 & 0,03137 & 0,00038 & 0,00435 \\
\hline 2012 & 0,01433 & 0,00793 & 0,05211 & 0,04077 & 0,00056 & 0,02303 & 0,01681 & 0,00454 & 0,00623 & 0,03325 & 0,00038 & 0,00467 \\
\hline 2013 & 0,01573 & 0,00866 & 0,06511 & 0,03659 & 0,00054 & 0,02119 & 0,01919 & 0,00425 & 0,00781 & 0,03573 & 0,00037 & 0,00269 \\
\hline 2014 & 0,01687 & 0,00965 & 0,09454 & 0,08200 & 0,00051 & 0,02038 & 0,01797 & 0,00402 & 0,00726 & 0,04316 & 0,00035 & 0,00298 \\
\hline 2015 & 0,02017 & 0,01077 & 0,10358 & 0,01526 & 0,00052 & 0,01578 & 0,01844 & 0,00375 & 0,01003 & 0,04398 & 0,00036 & 0,00290 \\
\hline 2016 & 0,02013 & 0,01149 & 0,05379 & 0,02521 & & 0,01460 & & & 0,00920 & 0,04607 & 0,00033 & 0,00378 \\
\hline 2017 & & 0,01295 & & & & & & & 0,00 & & 0,00034 & 0,00386 \\
\hline 2018 & 0,02244 & 0,01224 & 0,06434 & 0,30159 & 0,00058 & 0,02383 & 0,01924 & 0,00495 & 0,00763 & 0,11007 & 0,00034 & 0,00393 \\
\hline $\mathrm{S}^{*}$ & 0,02244 & 0,01295 & 0,10358 & 0,30159 & 0,00069 & 0,02746 & 0,02247 & 0,00495 & 0,01003 & 0,11007 & 0,00044 & 0,00467 \\
\hline 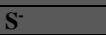 & 0,00196 & 0,00306 & 0,00223 & 0,00111 & 0,00046 & 0,00209 & 0,00180 & 0,00156 & 0,00222 & 0,00224 & 0,00033 & 0,00167 \\
\hline
\end{tabular}

\section{Adım 5: Ayırım Ölçütlerinin Hesaplanması:}

Her bir kriterin ait olduğu sütundaki değerlerden pozitif ve negatif ideal çözüm değerleri çıkarılarak sırası ile pozitif ve negatif ideal çözüme uzaklık değerleri tespit edilir. Pozitif ideal çözüme uzaklık değeri için eşitlik (7)'deki gibi, sütundaki değerler sırasıyla en büyük olan değerden çıkarılıp karesi alınmıştır. Negatif ideal çözüme uzaklık değerine ulaşmak için eşitlik (8)'deki gibi sütundaki değerler sırası ile en küçük değerlerden çıkarılıp karesi alınmıştır.

\section{Adım 6: İdeal Çözüme Yakınlığın Hesaplanması:}

Eşitlik (9) yardımıyla her bir alternatif değeri için negatif ideal çözüm değerini, kendi değeri ve aynı alternatifin pozitif ideal çözüm değerinin toplamına bölünmesiyle bulunmuştur. İdeal çözüm siralaması Tablo 10.'da gösterilmiştir.

Tablo 10. İdeal Çözüme Göre Yakınlı̆̆ın Hesaplanması

\begin{tabular}{|l|c|c|}
\hline YILLAR & C $^{*}$ & SIRALAMA \\
\hline $\mathbf{2 0 0 0}$ & 0,01433 & 17 \\
\hline $\mathbf{2 0 0 1}$ & 0,00888 & 18 \\
\hline $\mathbf{2 0 0 2}$ & 0,00877 & 19 \\
\hline $\mathbf{2 0 0 3}$ & 0,01783 & 16 \\
\hline $\mathbf{2 0 0 4}$ & 0,06824 & 14 \\
\hline $\mathbf{2 0 0 5}$ & 0,04822 & 15 \\
\hline $\mathbf{2 0 0 6}$ & 0,09911 & 11 \\
\hline $\mathbf{2 0 0 7}$ & 0,11696 & 10 \\
\hline $\mathbf{2 0 0 8}$ & 0,22640 & 6 \\
\hline $\mathbf{2 0 0 9}$ & 0,07949 & 13 \\
\hline $\mathbf{2 0 1 0}$ & 0,09694 & 12 \\
\hline $\mathbf{2 0 1 1}$ & 0,17940 & 9 \\
\hline $\mathbf{2 0 1 2}$ & 0,21705 & 7 \\
\hline $\mathbf{2 0 1 3}$ & 0,23453 & 5 \\
\hline $\mathbf{2 0 1 4}$ & 0,36602 & 3 \\
\hline $\mathbf{2 0 1 5}$ & 0,28040 & 4 \\
\hline $\mathbf{2 0 1 6}$ & 0,21153 & 8 \\
\hline $\mathbf{2 0 1 7}$ & 0,36732 & 2 \\
\hline $\mathbf{2 0 1 8}$ & 0,89199 & 1 \\
\hline
\end{tabular}


Tablo 10'a bakıldığında demir çelik üretim işletmesi en iyi performansını 2018 yılında göstermiştir. 2018 y1lını takiben en iyi performans gösteren y1llar ise 2017, 2014, 2015, 2013, 2008, 2012, 2066, 2011, 2007, 2006, 2010, 2009, 2004, 2005, 2003, 2000,2001 ve 2002 yillarıdır.

\subsection{ENTROPİ Ağırlıklarıyla MULTI-MOORA Yönteminin Uygulanması}

MULTI-MOORA yönteminin adımları aşağıda açıklanmıştır.

\section{Adım 1: Karar Matrisinin Hazırlanması:}

Demir çelik üretim işletmesinin 2000-2018 yılları arasındaki faaliyet raporları ve yetkililerden alınan verilere göre düzenlenen karar matrisi Tablo 3.' teki gibidir.

\section{Adım 2: Normalize Edilmiş Karar Matrisi:}

Matrisin hazırlanmasından sonra, MOORA yöntemlerinin kullanılması için eşitlik (10) yardımı ile normalleştirilmiş değerlere ait hesaplamalar yapılır. Normalize edilmiş karar matrisi Tablo 11'de gösterildiği gibidir.

Tablo 11. Normalize Edilmiş Karar Matrisi

\begin{tabular}{|c|c|c|c|c|c|c|c|c|c|c|c|c|}
\hline YILLAR & K1 & K2 & K3 & K4 & K5 & K6 & K7 & K8 & K9 & K10 & K11 & K12 \\
\hline 2000 & 0,10077 & 719 & \begin{tabular}{|c|}
0,01358 \\
\end{tabular} & 0,00324 & 0,28721 & 0,02902 & 0,04498 & 0,09786 & 0,11611 & \begin{tabular}{|l|}
0,01320 \\
\end{tabular} & 0,25365 & 0,21668 \\
\hline 2001 & 0,07314 & 0,12373 & \begin{tabular}{|l|}
0,01149 \\
\end{tabular} & \begin{tabular}{|l|}
0,00404 \\
\end{tabular} & 0,25810 & 0,03777 & 0,02801 & 0,13575 & 0,07887 & \begin{tabular}{|l|}
0,01875 \\
\end{tabular} & 0,23557 & 0,16913 \\
\hline 2002 & 0,03313 & 0,09038 & \begin{tabular}{|l|}
0,01378 \\
\end{tabular} & \begin{tabular}{|l|}
0,00982 \\
\end{tabular} & 0,23285 & 0,04131 & 0,03942 & 0,14177 & 0,10251 & \begin{tabular}{|l|}
0,01964 \\
\end{tabular} & 0,25521 & 0,11924 \\
\hline 2003 & 0,06142 & 0,13239 & \begin{tabular}{|l|}
0,01726 \\
\end{tabular} & \begin{tabular}{|c|}
0,00843 \\
\end{tabular} & 0,24348 & 0,05397 & 0,06193 & 0,14661 & 0,12725 & \begin{tabular}{|l|}
0,03687 \\
\end{tabular} & 0,23635 & 0,18351 \\
\hline 2004 & 0,13078 & 0,13724 & 0,04926 & 0,05638 & 0,23748 & 0,09698 & 0,10661 & 0,17018 & 0,14915 & 0,05743 & 0,26097 & 0,18 \\
\hline 2005 & 0,15853 & 0,15346 & 0,03015 & 0,00377 & 0,20807 & 0,14149 & 0,16389 & 0,18703 & 0,18841 & 0,05700 & 0,23830 & 0,21960 \\
\hline 2006 & 0,16887 & 0,17703 & 0,10603 & 0,05840 & 0,20249 & 0,17511 & 0,20061 & 0,21540 & 0,22973 & 0,08147 & 0,24356 & 0,2 \\
\hline 2007 & 0,16824 & 0,15949 & \begin{tabular}{|l|}
0,09211 \\
\end{tabular} & \begin{tabular}{|l|}
0,07893 \\
\end{tabular} & 0,19601 & 0,22785 & 0,26732 & 0,23424 & 0,26020 & \begin{tabular}{|l|}
0,08626 \\
\end{tabular} & 0,24914 & 0,19795 \\
\hline 2008 & 0,17363 & 0,16716 & 0,13224 & 0,18653 & 0,18953 & 0,38083 & 0,34955 & 0,27998 & 0,25350 & 0,01255 & 0,24349 & 0,12482 \\
\hline 2009 & 0,17845 & 0,17159 & 0,03954 & 0,03875 & 0,19720 & 0,22353 & 0,18515 & 0,26287 & 0,19516 & \begin{tabular}{|l|}
0,09213 \\
\end{tabular} & 0,22591 & 0,23636 \\
\hline 2010 & 0,18710 & 0,18727 & \begin{tabular}{|l|}
0,10332 \\
\end{tabular} & \begin{tabular}{|l|}
0,01647 \\
\end{tabular} & 0,24883 & 0,24800 & 0,23211 & 0,24746 & 0,20604 & \begin{tabular}{|l|}
0,11712 \\
\end{tabular} & 0,23095 & 0,25352 \\
\hline 2011 & 0,23246 & 0,22431 & \begin{tabular}{|l|}
0,11258 \\
\end{tabular} & \begin{tabular}{|l|}
0,12495 \\
\end{tabular} & 0,23778 & 0,30923 & 0,27523 & 0,25974 & 0,19934 & \begin{tabular}{|l|}
0,18469 \\
\end{tabular} & 0,22527 & 0,31091 \\
\hline 2012 & 0,24247 & 0,23438 & \begin{tabular}{|l|}
0,26840 \\
\end{tabular} & \begin{tabular}{|l|l|}
0,11882 \\
\end{tabular} & 0,23035 & 0,31932 & 0,26152 & 0,28472 & 0,22095 & \begin{tabular}{|l|}
0,19581 \\
\end{tabular} & 0,22193 & 0,33357 \\
\hline 2013 & 0,26615 & 0,25574 & 0,33533 & 0,10665 & 0,22227 & 0,29392 & 0,29845 & 0,26611 & 0,27722 & \begin{tabular}{|c|}
0,21039 \\
\end{tabular} & 0,21571 & 0,19222 \\
\hline 2014 & 0,28542 & 0,28505 & \begin{tabular}{|l|}
0,48694 \\
\end{tabular} & \begin{tabular}{|l|}
0,23900 \\
\end{tabular} & 0,20961 & 0,28266 & 0,27954 & 0,25211 & 0,25763 & \begin{tabular}{|l|}
0,25413 \\
\end{tabular} & 0,20325 & 0,21295 \\
\hline 2015 & 0,34131 & 0,31828 & 0,53350 & \begin{tabular}{|l|}
0,04447 \\
\end{tabular} & 0,21437 & 0,21879 & 0,28685 & 0,23511 & 0,35567 & \begin{tabular}{|l|}
0,25899 \\
\end{tabular} & 0,21099 & 0,20765 \\
\hline 2016 & 0,34065 & 0,33947 & \begin{tabular}{|l|}
0,27702 \\
\end{tabular} & 0,07347 & 0,23207 & 0,20248 & 0,25379 & 0,23711 & 0,32651 & \begin{tabular}{|l|}
0,27128 \\
\end{tabular} & 0,19366 & 0,27031 \\
\hline 2017 & 0,37648 & 0,38267 & \begin{tabular}{|l|}
0,20239 \\
\end{tabular} & 0,26863 & 0,24812 & 0,25021 & 0,28965 & 0,25675 & 0,30412 & \begin{tabular}{|l|}
0,46120 \\
\end{tabular} & 0,20140 & 0,27580 \\
\hline 2018 & 0,37970 & 0,36171 & \begin{tabular}{|c|}
0,33138 \\
\end{tabular} & \begin{tabular}{|l|}
0,87900 \\
\end{tabular} & 0,23926 & 0,33054 & 0,29931 & 0,31006 & 0,27054 & \begin{tabular}{|l|}
0,64813 \\
\end{tabular} & 0,19699 & 0,28099 \\
\hline
\end{tabular}

Adım 3: Ağırlıklandırılmış Karar Matrisi:

Ağırlıklandırılmış karar matrisi oluşturulurken Entropi yöntemiyle elde edilen ağırlıklar her bir kriter değeri ile çarpılarak ağırlıklandırılmış karar matrisi oluşturulmuştur. Ağırlıklandırılmış karar matrisi ve oran metodu matrisinin oluşumu Tablo 12.'de gösterilmiştir.

\section{Adım 4: Oran Metodunun Oluşturulması:}

MOORA yöntemlerinden biri olan Oran Yöntemi için eşitlik (11) yardımıyla Tablo 12. hazırlanmıştır. Optimizasyon işlemi yapılırken her bir alternatif için maksimum ve minimum değerler toplanır. Maksimum olan değerlerin toplamından minimum olan değerlerin toplamı çıkartılır. Daha sonra bu verilerle aşağıdaki Tablo 12. hazırlanır ve büyükten küçüğe sıralama işlemi yapılır.

Tablo 12. Ă̆ırlıklandırılmış Karar Matrisi ve Oran Matrisinin Oluşumu

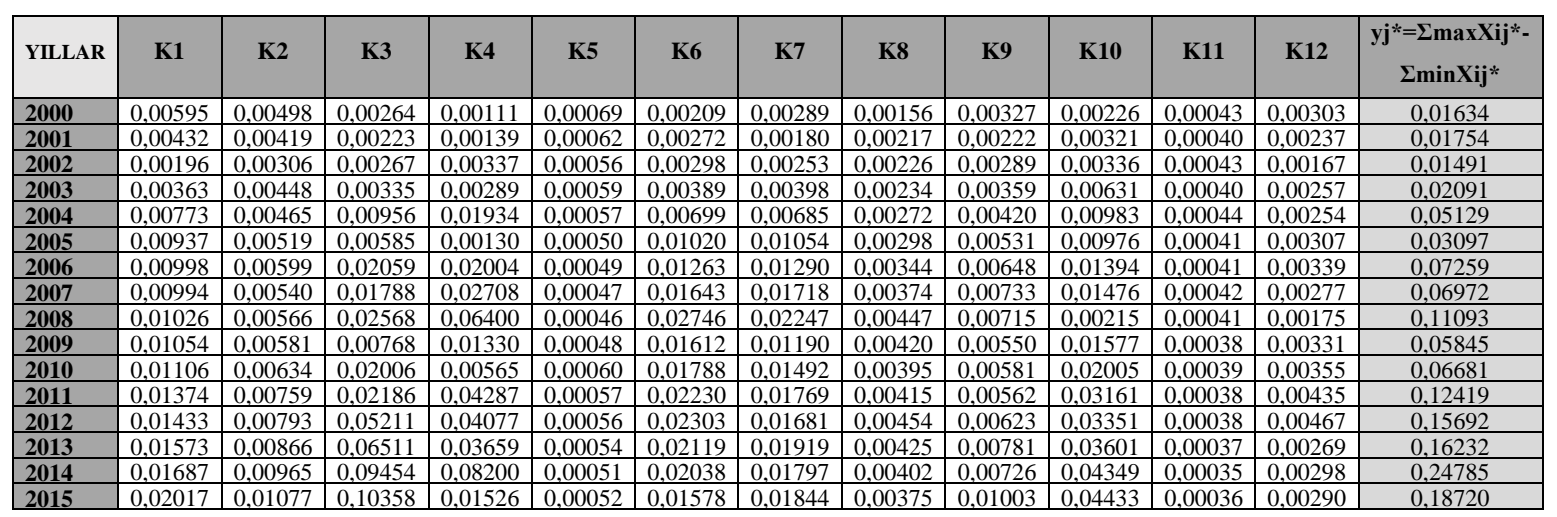


Amaç fonksiyon değerlerine göre her bir alternatif için maksimum olanlar toplanarak minimum olanlardan çıkarılma $\left(\mathrm{y}_{\mathrm{j}}{ }^{*}=\Sigma_{\max } X_{\mathrm{ij}}{ }^{*}-\Sigma_{\min } X_{\mathrm{ij}}{ }^{*}\right)$ işleminden sonra büyükten küçüğe sıralama yapılır. Sonuç olarak oran yöntemine göre sıralama Tablo 13.'de gösterildiği gibidir.

Tablo 13. Oran metodu siralaması

\begin{tabular}{|c|c|}
\hline YILLAR & ORAN METODU \\
\hline $\mathbf{2 0 0 0}$ & 18 \\
\hline $\mathbf{2 0 0 1}$ & 17 \\
\hline $\mathbf{2 0 0 2}$ & 19 \\
\hline $\mathbf{2 0 0 3}$ & 16 \\
\hline $\mathbf{2 0 0 4}$ & 14 \\
\hline $\mathbf{2 0 0 5}$ & 15 \\
\hline $\mathbf{2 0 0 6}$ & 10 \\
\hline $\mathbf{2 0 0 7}$ & 11 \\
\hline $\mathbf{2 0 0 8}$ & 9 \\
\hline $\mathbf{2 0 0 9}$ & 13 \\
\hline $\mathbf{2 0 1 0}$ & 12 \\
\hline $\mathbf{2 0 1 1}$ & 8 \\
\hline $\mathbf{2 0 1 2}$ & 6 \\
\hline $\mathbf{2 0 1 3}$ & 5 \\
\hline $\mathbf{2 0 1 4}$ & 2 \\
\hline $\mathbf{2 0 1 5}$ & 4 \\
\hline $\mathbf{2 0 1 6}$ & 7 \\
\hline $\mathbf{2 0 1 7}$ & 3 \\
\hline $\mathbf{2 0 1 8}$ & 1 \\
\hline
\end{tabular}

Oran Yöntemine göre sıralamaya bakıldığında Demir çelik üretim işletmesi en iyi performansını 2018 yılında göstermiştir. 2018 y1lını takiben en iyi performans gösteren y1llar ise 2014, 2017, 2015, 2013, 2012, 2016, 2011, 2008, 2006, 2007, 2010, 2009, 2004, 2005, 2003, 2001, 2002 ve 2000'dir.

\section{Adım 5: Referans Noktalarının Belirlenmesi:}

Eşitlik (12) yardımıyla normalize edilmiş karar matrisi üzerinden her amaç için ayrı olacak şekilde "Referans Noktaları" belirlenir. Referans noktaları belirlenirken her alternatife göre maksimum olanlar seçilmektedir.

\section{Adım 6: Referans Serisi Matrisinin Oluşturulması:}

Matristeki her değerin kendine ait referans noktasına uzaklığı eşitlik (13) yardımıyla tek tek belirlenerek Referans noktası matrisi Tablo 14.'de oluşturulmuş olur. Referans noktası matrisine göre her bir alternatifin maksimum değeri seçilip yazılır ve yazılan maksimum noktalara göre küçükten büyüğe alternatiflerin sıralaması yapılır. Sıralama Tablo 15.' de gösterilmiştir.

Tablo 14. Referans Serisi Oluşturulmuş Matris

\begin{tabular}{|c|c|c|c|c|c|c|c|c|c|c|c|c|c|}
\hline YILLAR & K1 & K2 & K3 & K4 & K5 & K6 & K7 & K8 & K9 & K10 & K11 & K12 & MAX \\
\hline 2000 & 0,01648 & 0,00797 & 0,10095 & 0,30048 & 0,00024 & 0,02537 & 0,00109 & 0,00339 & 0,00105 & 0,10867 & 0,00010 & 0,00163 & 0,30048 \\
\hline 2001 & 0,01811 & 0,00877 & 0,10135 & 0,30021 & 0,00017 & 0,02474 & 0,00000 & 0,00278 & 0,00000 & & 0,00007 & & 30021 \\
\hline 2002 & \begin{tabular}{|l|}
0,02048 \\
\end{tabular} & 0,00989 & \begin{tabular}{|l|}
0,10091 \\
\end{tabular} & 0,29822 & 0,00010 & \begin{tabular}{|l|}
0,02448 \\
\end{tabular} & 0,00073 & \begin{tabular}{|l|}
0,00269 \\
\end{tabular} & 0,00067 &, 10757 & 0,00010 & 0,00300 & 29822 \\
\hline 2003 & 0,01881 & 0,00847 & 0,10023 & 0,29870 & 0,00013 & 0,02357 & 0,00218 & 0,00261 & 0,00136 & 0,10462 & 0,00007 & 0,00210 & 29870 \\
\hline 2004 & 0,01471 & 0,00831 & 0,09402 & 0,28225 & 0,00012 & 0,02047 & 0,00505 & 0,00223 & 0,00198 & 0,10110 & 0,00011 & 0,00212 &, 28225 \\
\hline 2005 & 0,01307 & 0,00776 & 0,09773 & 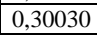 & 0,00004 & 0,01726 & 0,00874 & 0,00196 & 0,00309 & 0,10117 & 0,00008 & 0,00159 & 0,30030 \\
\hline 2006 & 0,01246 & 0,00696 & 0,08300 & 0,28156 & 0,00003 & \begin{tabular}{|c|}
0,01483 \\
\end{tabular} & 0,01110 & 0,00151 & 0,00425 & 0,09698 & 0,00008 & 0,00127 & 0,28156 \\
\hline 2007 & 0,01249 & 0,00756 & 0,08570 & 0,27451 & 0,00002 & 0,01103 & 0,01538 & 0,00121 & 0,00511 & 0,09616 & 0,00009 & 0,00190 & 0,27451 \\
\hline 2008 & 0,01218 & 0,00730 & 0,07791 & 0,23759 & 0,00000 & 0,00000 & 0,02067 & 0,00048 & 0,00492 & 0,10878 & 0,00008 & 0,00292 & 0,23759 \\
\hline 2009 & 0,01189 & 0,00715 & 0,09590 & 0,28830 & 0,00002 & 0,01134 & 0,01010 & 0,00075 & 0,00328 & 516 & 0,00005 & 36 &, 28830 \\
\hline 2010 & 0,01138 & 0,00661 & \begin{tabular}{|l|}
0,08352 \\
\end{tabular} & \begin{tabular}{|l|}
0,29594 \\
\end{tabular} & \begin{tabular}{|l|}
0,00014 \\
\end{tabular} & \begin{tabular}{|l|}
0,00958 \\
\end{tabular} & 0,01312 & \begin{tabular}{|l|}
0,00100 \\
\end{tabular} & 0,00358 & \begin{tabular}{|l|}
0,09088 \\
\end{tabular} & 0,00006 & 0,00112 & 0,29594 \\
\hline 2011 & 0,00870 & 0,00536 & 0,08172 & 0,25872 & 0,00012 & 0,00516 & 0,01589 & 0,00080 & 0,00340 & 0,07932 & 0,00005 & 0,00032 & 0,27639 \\
\hline 2012 & 0,00811 & 0,00502 & 0,05147 & 0,26082 & 0,00010 & 0,00444 & 0,01501 & 0,00040 & 0,00401 & 0,07741 & 0,00005 & 0,00000 & 0,26082 \\
\hline 2013 & 0,00671 & 0,00430 & 0,03848 & 0,26500 & 0,00008 & 0,00627 & 0,01739 & 0,00070 & 0,00559 & 0,07492 & 0,00004 & 0,00198 & 0,26500 \\
\hline 2014 & 0,00557 & 0,00330 & 0,00904 & \begin{tabular}{|l|}
0,21959 \\
\end{tabular} & 0,00005 & \begin{tabular}{|c|}
0,00708 \\
\end{tabular} & 0,01617 & 0,00092 & 0,00504 & 0,06743 & 0,00002 & 0,00169 & 0,21959 \\
\hline 2015 & 0,00227 & 0,00218 & 0,00000 & 0,28633 & 0,00006 & 0,01168 & 0,01664 & 0,00120 & 0,00780 & 0,06660 & 0,00003 & 0,00176 & 0,28633 \\
\hline 2016 & 0,00231 & 0,00146 & \begin{tabular}{|l|}
0,04980 \\
\end{tabular} & 0,27639 & 0,00010 & 0,0 & & & 0,00698 & & 0,00000 & 0,00088 & 0,25872 \\
\hline 2017 & 0,00019 & 0,00000 & 0,06429 & 0,20942 & 0,00014 & 0,00942 & 0,01682 & 0,00085 & 0,00635 & 0,03199 & 0,00001 & 0,00081 & 0,20942 \\
\hline 2018 & 0,00000 & 0,00071 & 0,03924 & 0,00000 & 0,00012 & 0,00363 & 0,01744 & 0,00000 & 0,00540 & 0,00000 & 0,00001 & 0,00074 & 0,03924 \\
\hline
\end{tabular}


Tablo 15. Referans Noktast Stralaması

\begin{tabular}{|c|c|}
\hline YILLAR & $\begin{array}{c}\text { REFERANS } \\
\text { NOKTASI }\end{array}$ \\
\hline $\mathbf{2 0 0 0}$ & 19 \\
\hline $\mathbf{2 0 0 1}$ & 17 \\
\hline $\mathbf{2 0 0 2}$ & 15 \\
\hline $\mathbf{2 0 0 3}$ & 16 \\
\hline $\mathbf{2 0 0 4}$ & 11 \\
\hline $\mathbf{2 0 0 5}$ & 18 \\
\hline $\mathbf{2 0 0 6}$ & 10 \\
\hline $\mathbf{2 0 0 7}$ & 8 \\
\hline $\mathbf{2 0 0 8}$ & 4 \\
\hline $\mathbf{2 0 0 9}$ & 13 \\
\hline $\mathbf{2 0 1 0}$ & 14 \\
\hline $\mathbf{2 0 1 1}$ & 9 \\
\hline $\mathbf{2 0 1 2}$ & 6 \\
\hline $\mathbf{2 0 1 3}$ & 7 \\
\hline $\mathbf{2 0 1 4}$ & 3 \\
\hline $\mathbf{2 0 1 5}$ & 12 \\
\hline $\mathbf{2 0 1 6}$ & 5 \\
\hline $\mathbf{2 0 1 7}$ & 2 \\
\hline $\mathbf{2 0 1 8}$ & 1 \\
\hline & \\
\hline
\end{tabular}

Referans Noktası Matrisine göre oluşturulan sıralamaya bakıldı ğında Demir çelik üretim işletmesi en iyi performansını 2018 yılında göstermiştir. 2018 yılını takiben en iyi performans gösteren y1llar ise 2017, 2014, 2008, 2016, 2012, 2013, 2007, 2011, 2006, 2004, 2015, 2009, 2010, 2002, 2003, 2001, 2005 ve 2000 ' dir.

\section{Adım 7: Tam Çarpım Formu:}

Karar matrisi üzerinden eşitlik (14) yardımıyla alternatifler ve kriterler birbirleriyle ilişkilendirilmiştir. K1 ve K2' nin değerleri maksimum-maksimum olduğu için karar matrisindeki değerleri birbiriyle çarpılır. Bunun sonucunda hesaplanmış olan $\mathrm{K} 1 * \mathrm{~K} 2$ değeri ile $\mathrm{K} 3$ formunun değeri de maksimum olduğu için $\left(\mathrm{K} 1{ }^{*} \mathrm{~K} 2\right)$ ile $\mathrm{K} 3$ çarpılır. $\mathrm{K} 5$ ' in değeri minimum olduğu için ise oluşan son değer K5'e bölünür. $\mathrm{Bu}$ işlemler maksimum değere sahip olan kriterlerde çarpılıp minimum değerde olan kriterlerde ise bölünerek devam etmektedir. Son olarak K12 kriteriyle de işlemler yapıldığında her bir kriter için sonuca ulaşılır ve bu sonuçlar büyükten küçüğe sıralanır. Tam Çarpım Formu sıralaması Tablo 16.'da gösterilmiştir.

Tablo 16. Tam Çarpım Formu Sıralaması

\begin{tabular}{|c|c|}
\hline YILLAR & TAM ÇARPIM FORMU \\
\hline $\mathbf{2 0 0 0}$ & 19 \\
\hline $\mathbf{2 0 0 1}$ & 17 \\
\hline $\mathbf{2 0 0 2}$ & 18 \\
\hline $\mathbf{2 0 0 3}$ & 16 \\
\hline $\mathbf{2 0 0 4}$ & 14 \\
\hline $\mathbf{2 0 0 5}$ & 15 \\
\hline $\mathbf{2 0 0 6}$ & 10 \\
\hline $\mathbf{2 0 0 7}$ & 11 \\
\hline $\mathbf{2 0 0 8}$ & 9 \\
\hline $\mathbf{2 0 0 9}$ & 13 \\
\hline $\mathbf{2 0 1 0}$ & 12 \\
\hline $\mathbf{2 0 1 1}$ & 8 \\
\hline $\mathbf{2 0 1 2}$ & 7 \\
\hline $\mathbf{2 0 1 3}$ & 6 \\
\hline $\mathbf{2 0 1 4}$ & 3 \\
\hline $\mathbf{2 0 1 5}$ & 4 \\
\hline $\mathbf{2 0 1 6}$ & 5 \\
\hline $\mathbf{2 0 1 7}$ & 2 \\
\hline $\mathbf{2 0 1 8}$ & 1 \\
\hline
\end{tabular}

Tam Çarpım Formuna göre sıralamaya bakıldığında Demir çelik üretim işletmesi en iyi performansını 2018 yılında göstermiştir. 2018 yılını takiben en iyi performans gösteren yıllar sırasıyla 2017, 2014, 2015, 2016, 2013, 2012, 2011, 2008, 2006, 2007, 2010, 2009, 2004, 2005, 2003 ve 2000’ dir. 


\section{Adım 8: Multimoora Siralaması:}

Moora Oran Yöntemi, Referans Noktası Yaklaşımı ve Tam Çarpım Formu yöntemleri uygulandıktan sonra, elde edilen sıralama değerleri ile bir baskınlık karşılaştırması yapılır. Baskınlık karşılaştırması sonucunda Tablo 17.'deki değerler elde edilerek Multi-Moora sıralama sonucuna ulaşılmıştır.

Tablo 17. MULTI-MOORA Sonuç Tablosu

\begin{tabular}{|c|c|c|c|c|}
\hline YILLAR & ORAN METODU & REFERANS NOKTASI & TAM ÇARPIM FORMU & MULTI-MOORA \\
\hline $\mathbf{2 0 0 0}$ & 18 & 19 & 19 & 19 \\
\hline $\mathbf{2 0 0 1}$ & 17 & 17 & 17 & 17 \\
\hline $\mathbf{2 0 0 2}$ & 19 & 15 & 18 & 18 \\
\hline $\mathbf{2 0 0 3}$ & 16 & 16 & 16 & 16 \\
\hline $\mathbf{2 0 0 4}$ & 14 & 11 & 14 & 14 \\
\hline $\mathbf{2 0 0 5}$ & 15 & 18 & 15 & 15 \\
\hline $\mathbf{2 0 0 6}$ & 1 & 10 & 10 & 10 \\
\hline $\mathbf{2 0 0 7}$ & 11 & 8 & 11 & 11 \\
\hline $\mathbf{2 0 0 8}$ & 9 & 4 & 9 & 9 \\
\hline $\mathbf{2 0 0 9}$ & 13 & 13 & 13 & 13 \\
\hline $\mathbf{2 0 1 0}$ & 12 & 14 & 12 & 12 \\
\hline $\mathbf{2 0 1 1}$ & 8 & 9 & 8 & 8 \\
\hline $\mathbf{2 0 1 2}$ & 6 & 6 & 7 & 6 \\
\hline $\mathbf{2 0 1 3}$ & 5 & 7 & 6 & 7 \\
\hline $\mathbf{2 0 1 4}$ & 2 & 3 & 3 & 3 \\
\hline $\mathbf{2 0 1 5}$ & 4 & 12 & 4 & 4 \\
\hline $\mathbf{2 0 1 6}$ & 7 & 5 & 5 & 2 \\
\hline $\mathbf{2 0 1 7}$ & 3 & 2 & 2 & 1 \\
\hline $\mathbf{2 0 1 8}$ & 1 & 1 & 1 & \\
\hline
\end{tabular}

Tablo 17.' ye bakıldığında en iyi sıralamaya sahip olan yıl 2018, en kötü sıralamaya sahip olan yıl ise 2000 yılı olmuştur. Baskınlık sonuçlarına bakıldığında Oran Yöntemi, Referans Noktası Matrisi ve Tam Çarpım Formu yöntemleri arasından sonuca en yakın olan yöntemin Tam Çarpım Formu olduğu görülmektedir. Moora Oran Yöntemi, Referans Noktası Yaklaşımı ve Tam Çarpım Formu yöntemleri kullanıldıktan sonra MULTI-MOORA Yöntemiyle baskınlık araştırması yapılarak bu sonuçlara ulaşı1mıştır.

\subsection{ENTROPİ Ağırlıklarıyla MAUT Yönteminin Uygulanması}

Demir çelik işletmesinin performansının değerlendirilmesinde kullanılan kriter ağılıkları ENTROPI yönteminden elde edildikten sonra MAUT yönteminde kullanılmıştır.

\section{Adım 1: Nitelik ve Kriterlerin Belirlenmesi}

Nitelik ve kriterlerin belirlenmesinde kullanılacak olan karar matrisi verileri aşağıdaki Tablo 3.'te görülmektedir.

\section{Adım 2: Ağırlık Değerlerinin 1'e Eşit Olması:}

Entropi yöntemi ile hesaplanan ağırlık değerlerinin toplamının 1'e eşit olması eşitlik (15) yardımıyla elde edilmiş olup Tablo 18.'de gösterilmiştir.

Tablo 18. Ăgırlı Değerlerinin Toplamı

\begin{tabular}{|l|c|c|c|c|c|c|c|c|c|c|c|c|c|}
\hline $\mathbf{w j}$ & 0,05909 & 0,03385 & 0,19416 & 0,34311 & 0,00241 & 0,07211 & 0,06429 & 0,01596 & 0,02819 & 0,17115 & 0,00170 & 0,01399 & $\Sigma=\mathbf{1}$ \\
\hline
\end{tabular}

\section{Adım 3: En İyi ve En Kötü Değer Atanması}

En iyi ve en kötü değer atamaları yapılırken her bir sütundaki en iyi değer kalın italik ve altı cizili , en kötü değer kalın ve italik yazı tipi ile yazılmış ve Tablo 19.'da gösterilmiştir.

Tablo 19. En İyi ve En Kötü Değerlerin Atanması

\begin{tabular}{|c|c|c|c|c|c|c|c|c|c|c|c|c|}
\hline YILLAR & K1 & K2 & K3 & K4 & K5 & K6 & K7 & K8 & K9 & K10 & K11 & K12 \\
\hline 2000 & 614309 & 894860 & 16941362 & 6016828 & 4834 & 1559 & 1932 & 6975 & 6223 & 113658328 & 7141 & 74,87 \\
\hline 2001 & 445894 & 752241 & 14333359 & 7508130 & 4344 & 2029 & 1203 & 9676 & 4227 & 161466920 & 6632 & 58,44 \\
\hline 2002 & 201995 & 549449 & 17192793 & 18242974 & 3919 & 2219 & 1693 & 10105 & $\overline{5494}$ & 169189513 & 7185 & 41,2 \\
\hline 2003 & 374464 & 804846 & 21544571 & 15666586 & 4098 & 2899 & 2660 & 10450 & 6820 & 317586275 & 6654 & 63,41 \\
\hline 2004 & 797261 & 834369 & 61472451 & 104737475 & 3997 & 5209 & 4579 & 12130 & 7994 & 494726176 & 7347 & 62,85 \\
\hline 2005 & 966471 & 932948 & 37622908 & 7012398 & 3502 & 7600 & 7039 & 13331 & 10098 & 491014440 & 6709 & 75,88 \\
\hline 2006 & 1029486 & 1076246 & 132320672 & 108486490 & 3408 & 9406 & 8616 & 15353 & 12313 & 701795904 & 6857 & 83,86 \\
\hline
\end{tabular}


Bir Demir Çelik İşletmesinin Performansının Çok Kriterli Karar Verme Yöntemleri İle Değerlendirilmesi

\begin{tabular}{|c|c|c|c|c|c|c|c|c|c|c|c|c|}
\hline 2007 & 1025675 & 969616 & 114946362 & 146639794 & 3299 & 12239 & 11481 & 16696 & 13946 & 743040715 & 7014 & 68,4 \\
\hline 2008 & 1058507 & 1016254 & 165030103 & 346531894 & $\underline{3190}$ & $\underline{20456}$ & 15013 & 19956 & 13587 & 1081439583 & 6855 & 43,13 \\
\hline 2009 & 1087893 & 1043150 & 49346211 & 71990373 & $\overline{3319}$ & 12007 & 7952 & 18736 & 10460 & 793562999 & 6360 & 81,67 \\
\hline 2010 & 1140614 & 1138473 & 128936931 & 30601713 & 4188 & 13321 & 9969 & 17638 & 11043 & 1008861255 & 6502 & 87,6 \\
\hline 2011 & 1417202 & 1363682 & 140496294 & 232120669 & 4002 & 16610 & 11821 & 18513 & 10684 & 1590849528 & 6342 & 107,43 \\
\hline 2012 & 1478184 & 1424886 & 334957800 & 220741196 & 3877 & 17152 & 11232 & 20294 & 11842 & 1686666273 & 6248 & 115,26 \\
\hline 2013 & 1622578 & 1554738 & 418478836 & 198125460 & 3741 & 15788 & 12818 & 18967 & 14858 & 1812224881 & 6073 & 66,42 \\
\hline 2014 & 1740055 & 1732970 & 607685115 & 443991991 & 3528 & 15183 & 12006 & 17969 & 13808 & 2188972410 & 5722 & 73,58 \\
\hline 2015 & 2080767 & 1934969 & 665788944 & 82619865 & 3608 & 11752 & 12320 & 16758 & 19063 & 2230892163 & 5940 & 71,75 \\
\hline 2016 & 2076736 & 2063827 & 345715634 & 136487839 & 3906 & 10876 & 10900 & 16900 & 17500 & 2336737097 & 5452 & 93,4 \\
\hline 2017 & 2295200 & 2326421 & 252570316 & 499049133 & 4176 & 13440 & 12440 & 18300 & 16300 & 3972625977 & 5670 & 95,3 \\
\hline 2018 & 2314794 & 2198974 & 413550136 & $\underline{1632956078}$ & 4027 & 17755 & 12855 & $\underline{22100}$ & 14500 & $\underline{5582800586}$ & 5546 & 97,09 \\
\hline
\end{tabular}

\section{Adım 4: Normalize Edilmiş Karar Matrisi:}

Normalizasyon işleminde eşitlik (16) yardımıyla öncelikle her nitelik için en iyi ve en kötü değerler belirlenerek en iyi değere 1 , en kötü değere ise 0 değeri atanır. Daha sonra diğer değerlerin hesaplanabilmesi için, hangi değer isteniyorsa o değerin o sütundaki en kötü değerden farkı, yine aynı sütundaki en iyi değerin en kötü değerden farkına bölünerek hesaplanmaktadır. Normalize edilmiş karar matrisi Tablo. 20' de gösterilmiştir.

Tablo 20. MAUT Yöntemine Göre Normalize Edilmiş Karar Matrisi

\begin{tabular}{|c|c|c|c|c|c|c|c|c|c|c|c|c|c|}
\hline YILLAR & K1 & K2 & $\mathbf{K 3}$ & K4 & K5 & $\overline{K 6}$ & K7 & K8 & K9 & K10 & K11 & K12 & TOPLAM \\
\hline 2000 & 0,011 & 0,0065 & 0,0007 & 0 & 0 & 0 & 0,0602 & 0 & 0,0244 & 0 & 0,0001 & 0,0063 & 0,11009 \\
\hline 2001 & 0,006 & 0,0038 & 0 & 0,0003 & 0,0007 & 0,0017 & 0,0642 & 0,0028 & 0,0281 & 0,0015 & 0,0006 & 0,0032 & 0,11423 \\
\hline 2002 & 0 & 0 & 0,0008 & 0,0025 & 0,0013 & 0,0025 & 0,0615 & 0,0033 & 0,0257 & 0,0017 & 0,0001 & 0 & 0,09984 \\
\hline 2003 & 0,004 & 0,0048 & 0,0021 & 0,0020 & 0,0010 & 0,0051 & 0,0562 & 0,0036 & 0,0232 & 0,0063 & 0,0006 & 0,0041 & 0,11444 \\
\hline 2004 & 0,016 & 0,0054 & 0,0140 & 0,0208 & 0,0012 & 0,0139 & 0,0456 & 0,0054 & 0,0210 & 0,0119 & 0 & 0,0040 & 0,16024 \\
\hline 2005 & 0,021 & 0,0073 & 0,0069 & 0,0002 & 0,0019 & 0,0230 & 0,0320 & 0,0067 & 0,0170 & 0,0118 & 0,0005 & 0,0065 & 0,13560 \\
\hline 2006 & 0,023 & 0,0100 & 0,0351 & 0,0216 & 0,0020 & 0,0299 & 0,0233 & 0,0088 & 0,0128 & 0,0184 & 0,0004 & 0,0080 & 0,19394 \\
\hline 2007 & 0,001 & 0,0080 & 0,0299 & 0,0296 & 0,0022 & 0,0407 & 0,0075 & 0,0102 & 0,0097 & 0,0197 & 0,0003 & 0,0051 & 0,16517 \\
\hline 2008 & 0,023 & 0,0088 & 0,0449 & 0,0718 & 0,0024 & 0,0721 & 0,0119 & 0,0137 & 0,0104 & 0,0302 & 0,0004 & 0,0003 & 0,26738 \\
\hline 2009 & 0,024 & 0,0094 & 0,0104 & 0,0139 & 0,0022 & 0,0398 & 0,0270 & 0,0124 & 0,0163 & 0,0212 & 0,0008 & 0,0076 & 0,18623 \\
\hline 2010 & 0,026 & 0,0112 & 0,0341 & 0,0051 & 0,0009 & 0,0448 & 0,0159 & 0,0112 & 0,0152 & 0,0280 & 0,0007 & 0,0087 & 0,20259 \\
\hline 2011 & 0,033 & 0,0155 & 0,0376 & 0,0476 & 0,0012 & 0,0574 & 0,0057 & 0,0121 & 0,0159 & 0,0462 & 0,0009 & 0,0125 & 0,28687 \\
\hline 2012 & 0,035 & 0,0166 & 0,0955 & 0,0452 & 0,0014 & 0,0595 & 0,0089 & 0,0140 & 0,0137 & 0,0492 & 0,0009 & 0,0139 & 0,35504 \\
\hline 2013 & 0,039 & 0,0191 & 0,1204 & 0,0405 & 0,0016 & 0,0542 & 0,0002 & 0,0126 & 0,0079 & 0,0531 & 0,0011 & 0,0047 & 0,34983 \\
\hline 2014 & 0,043 & 0,0225 & 0,1768 & 0,0923 & 0,0019 & 0,0519 & 0,0046 & 0,0116 & 0,0099 & 0,0649 & 0,0014 & 0,0061 & 0,48746 \\
\hline 2015 & 0,052 & 0,0264 & 0,1941 & 0,0161 & 0,0018 & 0,0388 & 0,0029 & 0,0103 & 0 & 0,0662 & 0,0012 & 0,0057 & 0,41651 \\
\hline 2016 & 0,052 & 0,0288 & 0,0987 & 0,0275 & 0,0013 & 0,0355 & 0,0107 & 0,0104 & 0,0029 & 0,0695 & 0,0017 & 0,0098 & 0,35565 \\
\hline 2017 & 0,058 & 0,0338 & 0,0710 & 0,1039 & 0,0009 & 0,0453 & 0,0022 & 0,0119 & 0,0052 & 0,1207 & 0,0015 & 0,0102 & 0,46565 \\
\hline 2018 & 0,059 & 0,0314 & 0,1189 & 0,3431 & 0,0011 & 0,0618 & 0 & 0,0159 & 0,0086 & 0,1711 & 0,0016 & 0,0105 & 0,82354 \\
\hline
\end{tabular}

\section{Adım 5: Fayda Matrisinin Belirlenmesi:}

Elde edilmiş her bir normalize değer eşitlik (17) yardımıyla ağırlık değerleri ile çarpılarak MAUT yönteminin fayda matrisini oluş̧urulmuş olur. Elde edilmiş fayda matrisi Tablo 21.'de gösterildiği gibidir.

Tablo 21. MAUT Yöntemine Göre Elde Edilmiş Fayda Matrisi

\begin{tabular}{|c|c|c|c|c|c|c|c|c|c|c|c|c|}
\hline YILLAR & K1 & $\mathrm{K} 2$ & K3 & K4 & K5 & K6 & K7 & K8 & K9 & K10 & K11 & K12 \\
\hline 2000 & 0,19515 & 0,19438 & 0,00400 & 0 & 0 & 0 & 0,93744 & 0 & 0,86546 & 0 & 0,10871 & 0,45463 \\
\hline 2001 & 0,11544 & 0,11412 & 0 & 0,00092 & 0,29805 & 0,02487 & 1 & 0,17858 & 1 & 0,00874 & 0,37731 & 0,23278 \\
\hline 2002 & 0 & 0 & 0,00439 & 0,00751 & 0,55657 & 0,03493 & \begin{tabular}{|l|}
0,95795 \\
\end{tabular} & 0,20694 & 0,91460 & 0,01015 & 0,08549 & 0 \\
\hline 2003 & 0,08163 & 0,14373 & 0,01107 & 0,00593 & 0,44769 & 0,07091 & 0,87496 & 0,22975 & 0,82522 & 0,03729 & 0,36570 & 0,29989 \\
\hline 2004 & 0,28174 & 0,16034 & 0,07236 & 0,06068 & 0,50912 & 0,19315 & 0,71026 & 0,34083 & 0,74609 & 0,06968 & 0 & 0,29233 \\
\hline 2005 & 0,36183 & 0,21582 & 0,03575 & 0,00061 & 0,81022 & 0,31968 & 0,49914 & 0,42023 & 0,60427 & 0,06900 & 0,33668 & 0,46827 \\
\hline 2006 & 0,39166 & 0,29646 & 0,18111 & 0,06298 & 0,86740 & 0,41525 & 0,36380 & 0,55392 & 0,45497 & 0,10754 & 0,25858 & 0,57602 \\
\hline 2007 & 0,03102 & 0,23645 & 0,15444 & 0,08643 & 0,93370 & 0,56517 & 0,11792 & 0,64271 & 0,34490 & 0,11508 & 0,17573 & 0,36727 \\
\hline 2008 & 0,40539 & 0,26270 & 0,23132 & 0,20930 & 1 & 1 & 0,18520 & 0,85825 & 0,36910 & 0,17695 & 0,25963 & 0,02606 \\
\hline 2009 & 0,41930 & 0,27783 & 0,05375 & 0,04055 & 0,92153 & 0,55289 & 0,42079 & 0,77759 & 0,57987 & 0,12432 & 0,52084 & 0,54645 \\
\hline 2010 & 0,44425 & 0,33148 & 0,17592 & 0,01511 & 0,39294 & 0,62243 & 0,24768 & 0,70499 & 0,54058 & 0,16368 & 0,44591 & 0,62652 \\
\hline 2011 & 0,57516 & 0,45821 & 0,19366 & 0,13897 & 0,50608 & 0,79648 & 0,08874 & 0,76284 & 0,56477 & 0,27010 & 0,53034 & 0,89427 \\
\hline 2012 & 0,60403 & 0,49266 & 0,49217 & 0,13198 & 0,58212 & 0,82516 & 0,13929 & 0,88060 & 0,48672 & 0,28762 & 0,57995 & 1 \\
\hline 2013 & 0,67237 & 0,56573 & 0,62037 & 0,11808 & 0,66484 & 0,75298 & 0,00318 & 0,79286 & 0,28343 & 0,31057 & 0,67230 & 0,34053 \\
\hline 2014 & 0,72797 & 0,66603 & 0,91081 & 0,26920 & 0,79440 & 0,72096 & 0,07286 & 0,72688 & 0,35421 & 0,37946 & 0,85752 & 0,43721 \\
\hline 2015 & 0,88923 & 0,77971 & 1 & 0,04708 & 0,74574 & 0,53940 & 0,04591 & 0,64681 & 0 & 0,38712 & 0,74248 & 0,41250 \\
\hline 2016 & 0,88733 & 0,85222 & 0,50868 & 0,08019 & 0,56448 & 0,49304 & 0,16778 & 0,65620 & 0,10535 & 0,40648 & 1 & 0,70483 \\
\hline 2017 & 0,99073 & 1 & 0,36570 & 0,30304 & 0,40024 & 0,62872 & 0,03562 & 0,74876 & 0,18624 & 0,70559 & 0,88496 & 0,73049 \\
\hline 2018 & 1 & 0,92828 & 0,61281 & 1 & 0,49088 & 0,85707 & 0 & 1 & 0,30756 & 1 & 0,95040 & 0,75466 \\
\hline
\end{tabular}

MAUT yöntemine göre elde edilmiş fayda matrisinde her bir alternatifin tüm değerleri toplanır ve büyükten küçüğe sıralama yapılır. Sıralama Tablo 22.'deki gibidir. 
Tablo 22. MAUT yöntemine göre siralama

\begin{tabular}{|c|c|}
\hline YILLAR & MAUT YÖNTEMI \\
\hline $\mathbf{2 0 0 0}$ & 18 \\
\hline $\mathbf{2 0 0 1}$ & 17 \\
\hline $\mathbf{2 0 0 2}$ & 19 \\
\hline $\mathbf{2 0 0 3}$ & 16 \\
\hline $\mathbf{2 0 0 4}$ & 14 \\
\hline $\mathbf{2 0 0 5}$ & 15 \\
\hline $\mathbf{2 0 0 6}$ & 11 \\
\hline $\mathbf{2 0 0 7}$ & 13 \\
\hline $\mathbf{2 0 0 8}$ & 9 \\
\hline $\mathbf{2 0 0 9}$ & 12 \\
\hline $\mathbf{2 0 1 0}$ & 10 \\
\hline $\mathbf{2 0 1 1}$ & 8 \\
\hline $\mathbf{2 0 1 2}$ & 6 \\
\hline $\mathbf{2 0 1 3}$ & 7 \\
\hline $\mathbf{2 0 1 4}$ & 2 \\
\hline $\mathbf{2 0 1 5}$ & 4 \\
\hline $\mathbf{2 0 1 6}$ & 5 \\
\hline $\mathbf{2 0 1 7}$ & 3 \\
\hline $\mathbf{2 0 1 8}$ & 1 \\
\hline
\end{tabular}

MAUT yöntemine göre sıralamaya bakıldığında demir çelik üretim işletmesi en iyi performansını 2018 yılında göstermiştir. 2018 yılını takiben en iyi performans gösteren yıllar sırasıyla 2014, 2017, 2015, 2016, 2012, 2013, 2011, 2008, 2010, 2006, 2009, 2007, 2004, 2005 ve 2003, 2011, 2000 ve 2002' dir.

\section{YÖNTEMLERIN KARŞILAŞTIRILMASI VE DEĞERLENDİRMESİ}

TOPSIS, MULTI-MOORA ve MAUT yöntemlerine göre Demir çelik üretim işletmesinin performansları MULTI-MOORA yöntemindeki baskınlık araştırmasına göre son değerlendirmesi yapılmıştır. (Tablo 23.)

Tablo 23. Yöntemlerin Karşılaştırılması ve Son Değerlendirme Tablosu

\begin{tabular}{|c|c|c|c|c|}
\hline YILLAR & TOPSIS & MULTI-MOORA & MAUT & BASKINLIK \\
\hline $\mathbf{2 0 0 0}$ & 17 & 19 & 18 & $\mathbf{1 8}$ \\
\hline $\mathbf{2 0 0 1}$ & 18 & 17 & 17 & $\mathbf{1 7}$ \\
\hline $\mathbf{2 0 0 2}$ & 19 & 18 & 19 & $\mathbf{1 9}$ \\
\hline $\mathbf{2 0 0 3}$ & 16 & 16 & 16 & $\mathbf{1 6}$ \\
\hline $\mathbf{2 0 0 4}$ & 14 & 14 & 14 & $\mathbf{1 4}$ \\
\hline $\mathbf{2 0 0 5}$ & 15 & 15 & 15 & $\mathbf{1 5}$ \\
\hline $\mathbf{2 0 0 6}$ & 11 & 10 & 11 & $\mathbf{1 1}$ \\
\hline $\mathbf{2 0 0 7}$ & 10 & 11 & 13 & $\mathbf{1 0}$ \\
\hline $\mathbf{2 0 0 8}$ & 6 & 9 & 9 & $\mathbf{9}$ \\
\hline $\mathbf{2 0 0 9}$ & 13 & 13 & 12 & $\mathbf{1 3}$ \\
\hline $\mathbf{2 0 1 0}$ & 12 & 12 & 10 & $\mathbf{1 2}$ \\
\hline $\mathbf{2 0 1 1}$ & 9 & 8 & 8 & $\mathbf{8}$ \\
\hline $\mathbf{2 0 1 2}$ & 7 & 6 & 6 & $\mathbf{6}$ \\
\hline $\mathbf{2 0 1 3}$ & 5 & 7 & 7 & $\mathbf{7}$ \\
\hline $\mathbf{2 0 1 4}$ & 3 & 3 & 2 & $\mathbf{3}$ \\
\hline $\mathbf{2 0 1 5}$ & 4 & 4 & 4 & $\mathbf{4}$ \\
\hline $\mathbf{2 0 1 6}$ & 8 & 5 & 5 & $\mathbf{5}$ \\
\hline $\mathbf{2 0 1 7}$ & 2 & 2 & 3 & $\mathbf{2}$ \\
\hline $\mathbf{2 0 1 8}$ & $\mathbf{1}$ & $\mathbf{1}$ & $\mathbf{1}$ & $\mathbf{1}$ \\
\hline
\end{tabular}

Demir çelik üretim işletmesinin 2000-2018 yılları arası performansının değerlendirilmesi uygulamasında Çok kriterli karar verme yöntemlerinden, TOPSIS, MULTI-MOORA ve MAUT; ağırlık hesaplama yöntemlerinden ise ENTROPİ kullanılmıştır. ENTROPİ TOPSIS, ENTROPİ MULTI-MOORA, ve ENTROPİ MAUT yöntemlerinin sonuçlarına göre üretim işletmesinin en iyi performans yılı 2018 olarak bulunmuştur. Bir sonraki aşama olan Tablo 23.'de gösterilen Yöntemlerin Karşılaştırılması Tablosuna bakıldığında TOPSIS, MOORA ve MAUT yöntemlerinin sonuçlarını karşılaştırmak ve nihai sonuca ulaşabilmek amacıyla MULTI-MOORA baskınlık yöntemi kullanılmıştır. MULTI-MOORA baskınlık yöntemi ile karşılaştırmanın yapılması sonucunda her üç 
yöntemin sonuç sıralamalarına bakıldığında 2018 yılının en iyi performans y1lı olarak belirlendiği görülmektedir. 2018 yılını takiben sirasiyla 2017, 2014, 2015, 2016, 2012, 2013, 2011, 2008, 2007, 2006, 2010, 2009, 2004, 2005 ve 2003, 2001 ve 2000'dir.

\section{SONUÇ, DEĞERLENDİRME VE ÖNERILER}

İşletmelerde performans değerlemesi çok boyutlu bir kavram olmakla birlikte birden fazla gösterge dikkate alınarak bu göstergeler bir bütün olarak değerlendirilmelidir. Çok kriterli karar verme yöntemleri ise bu anlamda, çok sayıda alternatif ve kriteri bir araya getirerek senkronize şekilde çözebilen yapıdadır. $\mathrm{Bu}$ nedenle, bu yöntemler farklı sektörlerde faaliyet gösteren işletmelerin performanslarının ölçülmesinde sıklıkla kullanılmaktadır.

Bu çalışmada bir Demir çelik üretim işletmesinin 2000-2018 yılları arasındaki performanslarının değerlendirilmesinde, ENTROPİ yöntemiyle belirlenen kriterlerin ağırlıkları hesaplanmıştır. Daha sonra ağırlık değerleri TOPSIS, MULTIMOORA ve MAUT tekniklerinde kullanılmıştır. Uygulamada; üretim, satış, faaliyet karı, çalışan sayısı, ihracat (ton), ithalat (ton), ihracat (Amerikan Doları), ithalat (Amerikan Doları), net satışlar, enerji tüketimi, kapasite kullanım oranı şeklinde 12 adet kriter kullanılmıştır. Uygulama sonucunda ise en iyi performansa sahip olan yılın 2018 olduğu görülmüştür. Bunun sebepleri incelendiğinde uygulamada kullanılan kriterlerden olan faaliyet karının diğer yıllardan daha yüksek olduğu, yatırımlar ve net satışların da 2018 yılında ikinci en büyük değerde olduğu görülmektedir. Entropi yönteminin sonucunda kriter ağırlık değerlerine bakıldığında da ağırlığı en yüksek olan ilk üç kriterin Faaliyet Karı, Yatırımlar ve Net Satışlar olduğu görülmektedir. Bu üç kriterin ağırlığının yüksek olması 2018 yılının en iyi performans yılı olmasını açıklar niteliktedir. Enerji tüketiminin sahip olduğu kriter ağırlık değerinin performans değerlemede öneminin düşük olduğu tespit edilmiş ve 2018 y1lında enerji tüketiminin diğer yıllarla karşılaştırıldığında daha az olması da 2018 yılının performansını olumlu şekilde etkilemiştir. 2000 yılına bakıldığında faaliyet karı ve net satış değerlerinin düşük olması ve enerji tüketimi değerlerinin yüksek olması performansı olumsuz etkilediği varsayılarak genel sıralamada gerilerde olmasını açıklamaktadır. 2004 yılından başlayarak 2010 yılına kadar çalışan sayısının teknolojik gelişmelere bağlı olarak giderek azalması ve bununla birlikte işletmenin performansının giderek artması gözlemlenmiştir.

2000-2018 yılları arasındaki performans değerlemesine bakıldığında üretim işletmesinin yaklaşan zamana göre performansının arttığı görülmekle birlikte; işletmenin performans durumuna pozitif ivme kazandırmak için net satışlarını, faaliyet karını ve yatırımlarını ve bu eksende satışlarını arttırmaya çabaladığı gözlemlenmiştir. Çok kriterli karar verme yöntemlerinin performans değerlemesinde seçilen kriterlerin işletmeler için değişiklik gösterebilir olması dikkate alarak birçok üretim işletmesi için uygulanabilir bir teknik olarak görülmektedir. Literatür incelemesi yapıldığında kriter ağırlıkları hesaplanırken ENTROPİ yönteminin sıklıkla kullanıldığı görülmektedir. ENTROPİ yöntemi ile kriter ağırlıklarının hesaplanması ve bu ağırlıkların TOPSIS, MULTIMOORA ve MAUT yöntemlerinde kullanılması ve sonuçların tutarlı olması çalışmanın farklılığını göstermektedir. Sonuç olarak ENTROPİ yöntemiyle kriter ağırlıkları hesaplanmış olup diğer üç çok kriterli karar verme yöntemi ile de 2018 yılının en iyi performans yılı olduğu sonucuna varılmış olup bu da çalışmanın tutarlılığını göstermektedir. Çok kriterli karar verme yöntemlerini kullanacak olan araştırmacıların farklı konulara yönelik yapacak olduğu çalışmalarda yöntemleri bir arada kullanılmanın sonuçlarda tutarlılık gösterip göstermeyeceğini sınamaları literatüre katkı sağlayıp faydalı olacaktır.

\section{Bilgilendirme / Acknowledgement:}

1- Araştırmacıların katkı oranı eşittir.

2- Bu çalışma, Süleyman Demirel Üniversitesi Sosyal Bilimler Enstitüsü İ̧̧letme Anabilim Dalı Üretim Yönetimi ve Sayısal Yöntemler Yüksek Lisans Programı kapsamında Aslı ÖZCAN'ın Prof. Dr. Nuri ÖMÜRBEK danışmanlığında yürüttüğ̈̈ 'Bir Demir Çelik İşletmesinin Performansının Çok Kriterli Karar Verme Yöntemleri İle Değerlendirilmesi” adlı tez çalışmasından üretilmiştir.

3- Makalenin yazarları arasında çıkar çatışması bulunmamaktadır.

4- Makalemizde etik kurulu izni ve/veya yasal/özel izin alınmasını gerektiren bir durum yoktur.

5- Bu makalede araştırma ve yayın etiğine uyulmuştur. 


\section{KAYNAKÇA}

Akyüz, Y., Bozdoğan, T. ve Hantekin, E., (2011). Topsis yöntemiyle finansal performansın değerlendirilmesi ve bir uygulama. Afyon Kocatepe Üniversitesi İktisadi ve İdari Bilimler Fakültesi Dergisi, 8(1), 73-92.

Baker, T. S. ve Cheng, R. H. (1996). A model-based approach for determining orientations of biological macromolecules imaged by cryoelectron microscopy. Journal of Structural Biology, 116(20), 120-130.

Ball1, S. (2005). Fuzzy çok kriterli karar verme ve basketbolda oyuncu seçimine uygulanması. Yayınlanmamış Yüksek Lisans Tezi, Muğla Sıtkı Koçman Üniversitesi Fen Bilimleri Enstitüsü, Muğla.

Brauers W. K. M., Zavadskas E. K., (2006). The Moora method and its application to privatization in a transition economy. Control and Cybernetics, 35(2), 445-469.

Brauers, W.K.M., Zavadskas, E. K., Peldschus, F. ve Turskis, Z., (2008). Multi-objective optimization of road design alternatives with an application of the moora method. The 25th International Symposium On Automation in Robotic in Construction, ISARC, June 26-29, 541-548.

Brauers, W. K. M., Zavadskas, Edmundas K., Turskis, Z. ve Vilutienė, T. (2008). Multi-objective contractor's ranking by applying the moora method. Journal Of Business Economics And Management, 9(4), 245-255.

Brauers, W. K. M., ve Ginevicius, R. (2010). The economy of the belgian regions tested with multimoora. Journal Of Business and Economics And Management, 11(2),173-209.

Bruyas, D. Dzida, D. ve Kraemer F. (2012). Evaluation of the quality of different samples of water using topsis method. University Of Natural Resources And Applied Life Sciences, Vienna, Austria, January, 1-7.

Canbolat Y. B., Chelst K. ve Garg N. (2007). Combining decision tree and maut for selecting a country for a global manufacturing facility. The International Journal Of Management Science, Omega $35,312-325$.

Canpolat, K., Canpolat, U., Özer, O. ve Demir, H. İ. (2015). Çok kriterli karar verme problemlerinin bütünleşik yöntemlerle çözümü için otomasyon geliştirme: bursiyer seçimi örneği. Akademik Platform Dergisi, Isites, Valencia-Spain, 538-547.

Çakır, S. ve Perçin, S., (2013). AB ülkeleri'nde bütünleşik entropi ağırlık-topsis yöntemiyle ar-ge performansının ölçülmesi. Uludă̆ Üniversitesi İktisadi ve İdari Bilimler Fakültesi Dergisi, 32(1), $77-95$.

Çakır, S. (2015). Bir toptan gıda işletmesinde bütünleşik shannon entropi-gri ilişkisel analiz yöntemiyle nakliye firması seçimi. Uludağ Üniversitesi İktisadi ve İdari Bilimler Fakültesi Dergisi, 35(1), 199-216.

Çınar, Y. (2004). Çok nitelikli karar verme ve bankaların mali performanslarının değerlendirilmesi örneği. Yayınlanmamış yüksek lisans tezi, Ankara Üniversitesi Sosyal Bilimler Enstitüsü İşletme Anabilim Dalı, Ankara.

Chatterjee P., Athawale V. M., ve Chakraborty S. (2010). Selection of industrial robots using compromise ranking and outranking methods. Robotics and Computer-Integrated Manufacturing, 26, 480-489.

Cho K. T. (2003). Multicriteria decision methods: an attempt to evaluate and unify. Matematical and Computer Modelling, 37, 1099-1119.

Çağıl, G., Türkmen Y1lmaz, S. (2012). İmkb’ye kote bilişim sektörü şirketlerinin finansal performanslarının topsis yöntemi ile değerlendirilmesi. Maliye Finans Yazıları, 26(95), 59-78. 
Demireli, E. (2010). Topsis çok kriterli karar verme sistemi: Türkiye'deki kamu bankaları üzerine bir uygulama. Girişimcilik ve Kalkınma Dergisi, 5(1), 101-112.

Gomez L. J. A., Arriaza M. ve Riesgo L. (2003). An MCDM analysis of agricultural risk aversion. European Journal Of Operational Research, 151, 569-585.

Görener, A., Dinçer H. ve Hacioğlu Ü. (2013). Application of multi-objective optimization on the basis of ratio analysis method for bank branch location selection. International Journal Of Finance \& Banking Studies, 2(2), 41-52.

Hafezalkotob, A. ve Hafezalkotob, A. (2016). Extended multimoora method based on shannon entropy weight for materials selection. Journal of Industrial Engineering International, 12, 1-13.

Ishizaka, A., Nemery P. (2013). Multi-criteria decision analysis : methods and software. First Edition. UK: John Wiley\&Sons Ltd. Published.

Kailiponi, P. (2010). Analyzing evacuation decisions using multi-attribute utility theory. International Conference On Evacuation Modeling And Management. Procedia Engineering 3, 163-174.

Kalibatas, D. ve Turskis, Z. (2008). Multicriteria evaluation of inner climate by using moora method. Journal Of Information Technology And Control, 37(1), 79-83.

Karaatlı, M. (2016). Entropi-gri ilişkisel analiz yöntemleri ile bütünleşik bir yaklaşım: turizm sektöründe uygulama. Süleyman Demirel Üniversitesi İktisadi ve İdari Bilimler Fakültesi Dergisi, 21(1), 6377.

Karaca, T. (2011). Proje yönetiminde çok kriterli karar verme tekniklerini kullanarak kritik yolun belirlenmesi. Yayımlanmamış yüksek lisans tezi, Gazi Üniversitesi, Ankara.

Karami, A. ve Johansson, R. (2014). Utilization of multi attribute decision making techniques to integrate automatic and manual ranking of options. Journal Of Information Science and Engineering, 30, 519-534.

Kracka, M., Brauers, W. K. M. ve Zavadskas, E. K. (2010). Ranking heating loses in a building by applying the multimoora. Journal of Engineering Economics, 21(4), 352-359.

Kim, K.S. ve Song, O. (2009). A maut approach for selecting a dismantling scenario for the thermal column in KRR-1. Annals Of Nuclear Energy, 36(2), 145-150.

L1, X., Wang, K., Liu, L. X., Jing, Y., H., ve Gao, C. (2011). application of the entropy weight and topsis method in safety evaluation of coal mines. Procedia Engineering, 26, 2085-2091.

Mahmoodzadeh, S., Shahrabı, J., Parrazar M., ve Zaerı, M. (2007). Project selection by using fuzzy ahp and topsis technique. International Journal of Humanities and Social Sciences, 1(3), 333-338.

Öktür, F. (2008), Yeni ürün geliştirme sürecinde tedarikçi bütünleşmesinin topsis yöntemi ile değerlendirilmesi. Yayınlanmamış yüksek lisans tezi, Kocaeli Üniversitesi, Kocaeli.

Ömürbek, V. ve Kınay, B. (2013). Havayolu taşımacıllı̆̆ sektöründe topsis yöntemiyle finansal performans değerlendirmesi. Süleyman Demirel Üniversitesi İktisadi ve İdari Bilimler Fakültesi Dergisi, 18(3), 343-363.

Önay, O. ve Çetin, E. (2012). Turistik yerlerin popülaritesinin belirlenmesi: İstanbul örneği. İstanbul Üniversitesi Isşletme Fakültesi İ̧sletme İktisadı Enstitüsü Dergisi, 23(72), 90-109.

Özgüven, N. (2011). Kriz döneminde küresel perakendeci aktörlerin performanslarının topsis yöntemi ile değerlendirilmesi. Atatürk Üniversitesi İktisadi ve İdari Bilimler Dergisi, 25(2), 151-162.

Öztel, A., Köse, M. S., Aytekin, İ. (2012). Kurumsal sürdürülebilirlik performansının ölçümü için çok kriterli bir çerçeve: Henkel örneği. Tarih Kültür ve Sanat Araştırmaları Dergisi, 1(4), 32-44.

Pawar, S., Singh, V., ve Devendra S. (2013). Digital camera evaluation base on ahp and topsis. International Journal Of Engineering Research, 2(2), 51-53. 
Saaty, T. L. (1994). Fundamentals of decision making and priority theory with the ahp. Pittsburgh, Pa, U.S.A.:Rws Publications, Interfaces.

Saldanl1, A. ve Sirma, İ. (2014). Topsis yönteminin finansal performans göstergesi olarak kullanılabilirliği. Marmara Üniversitesi Öneri Dergisi, 11(41), 185-202.

Sarıkaya, S. (2019). Doğu Anadolu Kalkınma Ajansı Demir Çelik Sektör Sanayi Raporu. 28 Aralık 2019 tarihinde Http://www.Dogaka.Gov.Tr/Icerik/Dosya/Www.Dogaka.Gov.Tr_523_Tn1d55sp adresinden erişildi.

Shih, H.S., Shyur, H.J.ve Lee, E. S. (2007). An extension of topsis for group decision making. Mathematical and Computer Modelling, 45, 801-813.

Soner, S. ve Önüt, S. (2006). Multi-criteria supplier selection: an electre-ahp application. Sigma Mühendislik ve Fen Bilimleri Dergisi, 4, 110-120.

Tekeş, M. (2002). Çok ölçütlü karar verme yöntemleri ve türk silahll kuvvetlerinde kullanılan tabancaların bulanık uygunluk indeksli analitik hiyerarşi prosesi ile karşılaştırılması. Yayımlanmamış yüksek lisans tezi, İstanbul Teknik Üniversitesi, İstanbul.

Ünal, Ö. F. (2010). Analitik hiyerarşi prosesi ile yetkinlik bazlı insan kaynakları yöneticisi seçimi. Yayımlanmamış doktora tezi, Süleyman Demirel Üniversitesi, Isparta.

Wang S. Q., Wee Y. P. ve Oforl G., (2002). Dssdss: A decision support system for dewatering systems selection. Building And Environment, 37, 625 - 645.

Wang, T. C. Ve Lee, H. D. (2009). Developing a fuzzy topsis approach based on subjective weights and objective weights. Expert Systems With Applications, 36, 8980-8985.

Yılmaz T. S. ve Çağıl, G. (2012). İmkb’ye kote bilişim sektörü şirketlerinin finansal performanslarının topsis yöntemi ile değerlendirilmesi. Maliye Finans Yazıları, 26(95), 60-76.

Yoon, K. P. ve Hwang, C. L., (1995). Multiple attribute decision making: an introduction. London: Sage University Paper Series on Quantitative Appplications in The Social Science.

Yue, Z. (2011). An extended topsis for determining weights of decision makers with interval numbers. Knowledge-Based Systems, 24, 146-153. 